University of Louisville

ThinkIR: The University of Louisville's Institutional Repository

Electronic Theses and Dissertations

$12-2007$

\title{
Young children's use of causal connections during storytelling : The role of context and individual differences in attention.
}

Danielle D. Brown

University of Louisville

Follow this and additional works at: https://ir.library.louisville.edu/etd

\section{Recommended Citation}

Brown, Danielle D., "Young children's use of causal connections during storytelling : The role of context and individual differences in attention." (2007). Electronic Theses and Dissertations. Paper 166. https://doi.org/10.18297/etd/166

This Doctoral Dissertation is brought to you for free and open access by ThinkIR: The University of Louisville's Institutional Repository. It has been accepted for inclusion in Electronic Theses and Dissertations by an authorized administrator of ThinkIR: The University of Louisville's Institutional Repository. This title appears here courtesy of the author, who has retained all other copyrights. For more information, please contact thinkir@louisville.edu. 
YOUNG CHILDREN'S USE OF CAUSAL CONNECTIONS DURING STORYTELLING: THE ROLE OF CONTEXT AND INDIVIDUAL DIFFERENCES IN ATTENTION

\author{
By \\ Danielle D. Brown \\ B.A., American University, 2003 \\ M.A., University of Louisville, 2005

\begin{abstract}
A Dissertation
Submitted to the Faculty of the

Graduate School of the University of Louisville in Partial Fulfillment of the Requirements for the Degree of
\end{abstract} \\ Doctor of Philosophy \\ Department of Psychological and Brain Sciences \\ University of Louisville \\ Louisville, Kentucky
}

December 2007 

Copyright 2007 by Danielle D. Brown

All rights reserved 
YOUNG CHILDREN'S USE OF CAUSAL CONNECTIONS DURING STORYTELLING: THE ROLE OF CONTEXT AND INDIVIDUAL DIFFERENCES IN ATTENTION

\author{
By \\ Danielle D. Brown \\ B.A., American University, 2003 \\ M.A., University of Louisville, 2005 \\ A Dissertation Approved on
}

October 16, 2007

by the following Dissertation Committee:

Dissertation Director 


\section{DEDICATION}

This dissertation is dedicated to my beloved uncle

Daryl A. Brown

who was closer than a brother. He is remembered for his unconditional love, humor, and support. I will miss and love him forever.

And to my family

George W. and Esther B. Jones

Sharon Fleming

Guy and Gail Brown

Michelle and Allisa Fleming

for their encouragement and unfettered support of my educational and professional

aspirations. 


\section{ACKNOWLEDGEMENTS}

I look forward to a future career in research with excitement thanks to the scaffolding, educational and professional advice, and persistence of my mentor, Dr. Barbara M. Burns. Her insight into the challenges faced by women in the workplace and insistence that I can do better has helped me improve my skills as a professional. I would also like to thank my dissertation committee for the guidance and thoughtful questions. I have learned much about myself and research career goals during this process. I am extremely appreciative of Dr. Deborah Winders Davis for her help and selflessness during the last four years.

I am grateful to those students with whom I have shared this experience. Special thanks to Ruby C. Harris and Kristy Matala for the social network of support they provided as I adjusted to a new environment and expectations and faced challenges. 


\section{ABSTRACT \\ YOUNG CHILDREN'S USE OF CAUSAL CONNECTIONS DURING STORYTELLING: THE ROLE OF CONTEXT AND INDIVIDUAL DIFFERENCES IN ATTENTION}

\section{Danielle D. Brown}

October 16, 2007

Narrative causal understanding is related to a variety of school-related skills such as reading comprehension, and memory. Previous research shows a developmental trend in the ability to use and understand causal connections that begins at age 4 and continually improves up through ages 10 and 11 . Researchers posit that this developmental trend in one aspect of narrative ability is explained by an increase in narrative knowledge; children learn more about what is required in narratives they get older. There is a dearth of research on other possible influences on narrative ability. In two experiments, the current study uses a storytelling procedure to investigate narrative ability and causal understanding in 58 preschool children based on a conceptual model of early causal understanding in discourse. In the first experiment it was hypothesized that both individual and age-related differences will be observed in the complexity of causal connections children produce and the distance over which children causally connect. Variations in stimulus complexity (i.e., complexity of the goals of each story) were expected to account for differences in the production of causal connections. In the second experiment it was hypothesized that individual differences in skills related to three attention networks can explain differences in causal understanding. The results show that 
3-year-olds can use causal connections during storytelling and that patterns of age-related increases differ depending on the connection type and narrative context. The results also show that attention skills influence specific aspects of causal understanding. The results are consistent with previous storytelling research and research with children diagnosed with ADHD. The current study illustrates the importance of investigating a variety of contextual and child factors that may impact the development of children's causal understanding. Implications for future research and the development early intervention programs are discussed. 
TABLE OF CONTENTS

PAGE

DEDICATION

ACKNOWLEDGEMENTS

ABSTRACT

LIST OF TABLES

LIST OF FIGURES

iii

iv

$\mathrm{v}$

ix

xi

INTRODUCTION 1

$\begin{array}{ll}\text { EXPERIMENT } 1 & 21\end{array}$

$\begin{array}{ll}\text { METHOD } & 25\end{array}$

$\begin{array}{ll}\text { Participants } & 25\end{array}$

$\begin{array}{ll}\text { Materials } & 26\end{array}$

$\begin{array}{ll}\text { Procedure } & 27\end{array}$

$\begin{array}{ll}\text { Coding Procedure } & 28\end{array}$

Reliability analyses 33

$\begin{array}{ll}\text { RESULTS } & 34\end{array}$

$\begin{array}{ll}\text { Preliminary Analyses } & 34\end{array}$

Variable Manipulation and Analysis Interpretation 35

$\begin{array}{ll}\text { Hypothesis } 1 & 37\end{array}$

$\begin{array}{ll}\text { Hypothesis } 2 & 38\end{array}$

$\begin{array}{ll}\text { Hypothesis } 3 & 41\end{array}$

Hypothesis $4 \quad 43$ 
$\begin{array}{ll}\text { DISCUSSION } & 47\end{array}$

$\begin{array}{ll}\text { EXPERIMENT } 2 & 52\end{array}$

$\begin{array}{ll}\text { METHOD } & 54\end{array}$

Participants $\quad 55$

Materials $\quad 55$

$\begin{array}{ll}\text { Procedure } & 55\end{array}$

$\begin{array}{ll}\text { RESULTS } & 57\end{array}$

$\begin{array}{ll}\text { Preliminary Analyses } & 57\end{array}$

Variable Manipulation and Analysis Interpretation 58

Hypothesis $1+59$

$\begin{array}{ll}\text { Hypothesis } 2 & 61\end{array}$

$\begin{array}{ll}\text { DISCUSSION } & 61\end{array}$

$\begin{array}{ll}\text { CONCLUSION } & 66\end{array}$

$\begin{array}{ll}\text { REFERENCES } & 75\end{array}$

$\begin{array}{ll}\text { APPENDIX } & 87\end{array}$

CURRICULUM VITA 110 


\section{LIST OF TABLES}

TABLE

PAGE

1. Descriptions of Storytelling Variables Measured from the Storytelling Procedure

2. Intra-Correlations Measuring Reliability for Storytelling Variable

3. Storytelling Means and Standard Deviations According to Gender

4. Storytelling Means and Standard Deviations According to Age

5. Correlations between Chronological Age and Storytelling Variables

6. Summary of Linear Regression Analysis for Variables Predicting Children's Use of Physical and Psychological Connections at the Initial Assessment

7. Summary of Linear Regression Analysis for Variables Predicting Children's Use of Within-Scene and Between-Scene Connections at the Initial Assessment

8. Correlations between Goal Complexity and Storytelling Variables that Control for Chronological Age

9. Summary of Hierarchical Regression Analysis for Variables Predicting Children's Use of Motivational Connections at the Initial Assessment

10. Summary of Multiple Regression Analysis for Variables Predicting Children's Use of Psychological Connections at the 6-Month Assessment

11. Summary of Multiple Regression Analysis for Variables Predicting Children's Production of an Overall Goal at the 6-Month Assessment 
12. Descriptions of Attention Variables Measured During the Three Attention Games

13. Attention Game Means and Standard Deviations for the Entire Sample and According to Gender

14. Correlations among Chronological Age and Attention Game Variables

15. Correlations between Attention Game and Storytelling Variables at the Initial Assessment that Control for Chronological Age and Vocabulary

16. Summary of Linear Regression Analysis for Variables Predicting the Distance of Children's Causal Connections at the Initial Assessment

17. Correlations between Attention Game and Storytelling Variables at the 6Month Assessment that Control for Chronological Age, Vocabulary, and Initial Performance 


\section{LIST OF FIGURES}

$\begin{array}{ll}\text { FIGURE } & \text { PAGE }\end{array}$

1. Conceptual Model of Early Causal Understanding in Discourse 87

2. Causal discourse analysis of A Boy, a Dog, and a Frog 88

3. Testing Model of Early Causal Understanding 89

4. Production of Four Types of Causal Connections 94

5. Production of Psychological Connections by Goal Complexity at Initial Assessment

6. Production of Motivational Connections by Goal Complexity at Initial Assessment 


\section{INTRODUCTION}

Causal understanding, the ability to use and understand causal information, is an important skill that contributes to a variety of other pre-academic skills. A large body of research shows that causal understanding is important for the production and understanding of narrative (Trabasso, 1994; Suh \& Trabasso, 1993; Trabasso \& Suh, 1993). Within this type of discourse, the ability to understand causal information is measured by the ability to use and comprehend causal connections. Trabasso (1994) states that the ability to interpret or produce an effective narrative lies in the producer's ability to make it coherent, which is achieved by making inferences that connect ideas, about time and place of actions, about characters, etc (Suh \& Trabasso, 1993; Trabasso \& Suh, 1993). These inferences that connect the ideas, time, actions, characters, etc. within narrative are termed causal connections and are the main contribution to the causal coherence of narratives.

Research shows that causal connections are used in the memory and comprehension of narrative. Adults recall and comprehend information that is causally connected more often than information that is unconnected (Rizella \& O'Brien, 1996; van den Broek, Lorch, \& Thurlow, 1996; van den Broek \& Trabasso, 1986; Trabasso \& van den Broek, 1985) and are more likely to include causally connected material when writing (van den Broek, Linzie, Fletcher, \& Marsolek, 2000). When evaluating information in narrative, children and adults are more likely to rate causally connected information as more important than unconnected information (Wolman, 1991; van den 
Broek, 1989; Trabasso \& Sperry, 1985; Trabasso \& van den Broek, 1985). Other research shows that children developing typically and children with disabilities also use causal connections in tasks of recall and comprehension (Lorch, O'Neil et al., 2004; Lorch, Diener et al., 1999; Lorch, Sanchez et al., 1999; Wolman, van den Broek, \& Lorch, 1997; van den Broek et al., 1996; Wolman, 1991; van den Broek, 1989; Trabasso, Secco, \& van den Broek, 1984). Little is known, however, about the use and understanding of causal connections in very young children. Existing research has described age differences in the use of causal relations, but no information about individual differences has been reported (Berman \& Slobin, 1994; Trabasso, Stein, Rodkin, Munger, \& Baughn, 1992; Trabasso \& Nickels, 1992; Berman, 1988). A better understanding of the use of causal relations in preschool children has implications for knowledge concerning the development of causal understanding, factors that influence this development and individual differences in causal understanding, and additional factors that may influence memory and comprehension.

One factor that may contribute to the development of causal understanding is attention. The link between attention skills and causal understanding is suggested by research with children diagnosed with ADHD (Lorch, O’Neil et al., 2004; Lorch, Diener et al., 1999; Lorch, Sanchez et al., 1999) and research showing relations between attention and school achievement, in particular reading achievement (Burns et al., 2007; Rabiner, Coie, \& The Conduct Problems Prevention Research Group, 2000; Rapport, Scanlan, \& Denney, 1999; de Jong, 1993; Fergusson \& Horwood, 1992). No study has examined how the attention of children without diagnosed attention deficits influences causal understanding. The model of early causal understanding in Figure 1 proposes that 
child cognitive skills, particularly attention skills, impact school readiness and achievement directly and through early causal understanding. The current study operates within this model to describe individual differences in the development of causal understanding by employing storytelling and CDA coding procedures, identifying factors that influence the use of causal understanding, and examining individual differences in attention as another influence for individual differences in early causal understanding in discourse.

The Use of Causal Connections in Young Children

Studies of narrative causal understanding in very young children often use storytelling procedures to elicit narratives, which are examined for their causal coherence (e.g., Trabasso \& Nickels, 1992). Causal discourse analysis (CDA) is a coding procedure used to identify the causal structure of narratives (Trabasso \& Wiley, 2005; Trabasso \& Nickels, 1992; Trabasso, van den Broek, \& Suh, 1989; Trabasso \& van den Broek, 1985). $\mathrm{CDA}$ is performed on a text representation of a narrative and depicts the causal connections between the goals, attempts, and outcomes (Trabasso \& Nickels, 1992). Figure 2 depicts a CDA for a set of clauses from a narrative based on a wordless picture book. Causal connections are represented by the arrows between clauses, which point from the antecedent to the consequence. In this analysis, causal connections are determined by necessary and sufficiency criteria (Trabasso et al., 1989).

Several studies employing storytelling and CDA procedures have shown large age differences in the ability to make causal connections during story narration. Specifically, 3- and 4-year-old children tend to produce fewer connections than older children and adults (Trabasso \& Nickels, 1992; Trabasso, et al., 1992). The studies conclude that 4- 
year-olds are able to make causal connections, but do so inconsistently. This is confirmed by research showing that 4-year-olds can use causal connections in recall, but less reliably than 6-year-olds and adults (van den Broek, 1996). In contrast, 3-year-olds are reported not to have this ability (Trabasso \& Nickels, 1992; Trabasso, et al., 1992). Research by Berman (1988; Berman \& Slobin, 1994) suggests that the development of narrative ability does not begin until age 5 . She concludes that 3 - and 4-year-olds lack grammatical knowledge, but 5- and 7-year olds know what is expected during storytelling.

Although there is evidence of a developmental trend, the research does not provide consensus as to when causal understanding begins to develop. Some research even suggests that children younger than age 3 can use causal connections in imitation and recall under different situations (Wenner \& Bauer, 1999; Travis, 1997; Bauer, 1992). For example, Bauer and Shore (1987) found that infants between 17 and 20 months recalled more actions and the order of pairs of actions for novel, causally connected sequences compared to novel, arbitrarily ordered sequences. Other research shows that 15-month-old children can identify causes in causal chains (Cohen, Rundell, Spellman, \& Cashon, 1999). This research indicates that children younger than 3-years-old can use causal connections in tasks with physical objects, which implies a causal understanding at an age earlier that what is proposed in the storytelling literature.

The current study extends the previous research by examining individual differences in the use of causal connections in preschool age children. A review of the literature suggests that causal understanding in discourse may begin to develop between the ages 3 and 5 and that three factors, in addition to age, influence this understanding. 
The three factors include the complexity level of causal connections, the distance over which connections must be made, and the narrative context, which may all impact the use of causal relationships by young children. Previous research suggests that age is perhaps the most influential factor in children's production of story narratives. However, examinations into the role of other factors are either sparse or inconsistent. The model that is tested in the current study is shown in Figure 3. The model shows how the three factors and age may influence causal understanding during the early stages of its development. The current study uses this framework, based on suggestions made by previous research, to tests the relations among these factors.

\section{Complexity of Connections}

The increasing ability to understand and communicate more complex causal connections can serve as evidence of increasing causal understanding. This is supported by research indicating that some types of causal connections are evidenced at younger ages than others. Four-year-olds are more likely than 3-year-olds to refer to the overall plot of a wordless picture book (Berman, 1988), relate the characters in a story (Trabasso et al., 1992), connect statements of attempts with purposes (Trabasso et al., 1992), and relate stories to a conclusion (Trabasso et al., 1992). Four-year-olds also tend to produce more attempts in general (Trabasso \& Nickels, 1992) and mention more initiating events (Trabasso et al., 1992). This suggests that these types of causal connections are more developed at age 4 than at age 3 and begin to develop during the preschool years. Threeand 4-year-olds perform similarly, but worse than older children and adults, at reinstating goals after failed attempts (Trabasso et al., 1992), producing goal-attempt-outcome (GAO) episodes (Trabasso \& Nickels, 1992), and referring to the overall theme (Berman, 
1988). The use of connections in these instances may not develop until after age 4. For example, 3-and 4-year-olds may be equally poor at making goal-related connections after failed attempts to achieve the goal. Although these studies suggest that connections develop at different ages depending on type, they lack a method for defining and investigating the complexity of the different types of connections.

Trabasso et al. (1989) defines four types of connections that provide a method for studying the complexity of causal connections. Connections are categorized as enabling, physical, motivational, and psychological based on two criteria. The necessity criterion employs the counterfactual tests that if A (the antecedent) had not happened in the story, than $B$ (the consequence) would not have happened. The sufficiency criterion states that the occurrence of $A$ leads to the inevitable occurrence of $B$. Physical, motivational, and psychological relations found in narratives fulfill both causal criteria. Enabling relations, however, only fulfill the necessity criterion. The former three types of connections do not differ on the two criteria, but in the type of information contained in $A$ and $B$. Physical connections contain no goal information or internal states whereas motivational connections contain goal information in the antecedent $(A)$ and psychological connections contain internal states or reactions in the consequence (B). Figure 2 labels each causal connection by type for a set of narrative clauses ( $e$ for enabling, phi for physical, $m$ for motivational, and psi for psychological).

These definitions of four types of connections suggest that enabling relations are the least complex and that motivational and psychological relations are the most complex. This is also suggested by research with infants, which indicates that the use of enabling relations may develop prior to other connections. Children as young as 16 and 
20 months are able to imitate events with enabling relations compared to temporally ordered, but arbitrarily related events (Wenner \& Bauer, 1999; Bauer, 1992). Compared to arbitrarily ordered events, the exact sequence is necessary to the final product in events with enabling relations. Travis (1997) demonstrated 24-month-old children's understanding of enabling relationships through their imitation and clustering of events around goals. This suggests that infants can not only imitate causal relationships within a sequence, but also make use of those relationships in order to complete a task. Similarly, research with older children and adults shows that causal relationships are used to remember and comprehend information (Lorch, Diener et al., 1999; Lorch, Sanchez et al., 1999; Rizella \& O’Brien, 1996; van den Broek \& Trabasso, 1986; Trabasso \& van den Broek, 1985; Trabasso et al., 1984).

Trabasso and Nickels (1992) examined the relative frequencies of the four types of relations in story narratives. Enabling relations were utilized more than other relations within episodes that contained a goal, attempt, and outcome (GAO episodes) for all ages. Three- to 5-year-old children relied more on enabling relations than older individuals. Enabling, psychological, and motivational connections were utilized equally between GAO episodes. Physical connections were not used at all. For 4-year-olds, however, enabling relations were most frequent and motivational relations were less frequent. Although the Trabasso and Nickels (1992) study finds that younger children rely more on enabling connections, their analyses is limited to the number of connections that occur within and between GAO episodes. The ability to produce such episodes is limited in preschool children. Three- to 5-year-old children produced more non-GAO episodes than GAO episodes (Trabasso \& Nickels, 1992). Analyses of the production of causal 
connections according to GAO episodes may underestimate the ability of preschool children. Therefore, it is unclear as to the role of the different types of connections in the development of causal understanding. Studies that investigate the use and understanding of each type of causal relations in a more age-appropriate way are needed. The current study describes individual differences in the productions of enabling, physical, motivational, and psychological connections independent of GAO episodes.

Narrative Distance and Causal Connections

Previous research also examines the influence of narrative distance on the ability to make causal connections as evidence of increasing causal understanding. To measure narrative distance, connected events, ideas, goals, etc. are often categorized in terms of local or global distance. For example, in aurally presented narratives, local narrative distance describes events that are causally connected but occur temporally close together compared to global narrative distance that describes events that are connected but occur temporally far apart. Narrative distance may also be measured continuously by the number of clauses or idea units between two connected events.

Berman and Slobin (1994) investigated the global and local structuring of narratives produced by 3-, 4-, 5-, 9-year-old, and adult speakers of five different languages. An average of $14 \%$ of 3 -year-olds, $33 \%$ of 4 -year-olds, $57 \%$ of 5 -year-olds, $85 \%$ of 9 -year-olds, and $97 \%$ of adults mentioned at least one of three components needed for global structure (i.e., plot onset, plot unfolding, and plot resolution). The percentages decreased when the researchers examined whether all three components were mentioned to $3 \%$ of 3 -year-olds, $14 \%$ of 4 -year-olds, $34 \%$ of 5 -year-olds, $66 \%$ of 9 -yearolds, and $92 \%$ of adults. The results indicate that preschool children could make 
connections globally, but rarely connected all the pieces of the story. Furthermore, 5year-olds could include all three components into global structure, but did so inconsistently.

To assess local structure, narratives were examined for components that connected the actions, states, and characters of a single page (Berman \& Slobin, 1994). Three- and 4-year-old children were more likely to mention none of the components or only those containing background elements. Five-year-olds mostly narrated the plotadvancing components and rarely mentioned the background elements. Adults and 9year-olds narrated plot-advancing components and rarely narrated other components. Furthermore, 9-year-olds and adults were the only participants to narrate motivational components. Local structure was further assessed by examining the connections individuals narrated between two pages of the wordless picture book. Three- and 4-yearolds were less likely to connect the pages, although some 4-year-olds implied relations. A few 5-year-olds, half the 9-year-olds, and most adults produced statements that connected the pages. Although Berman (2004) posits that the organization of narrative begins with a sequential chaining stage, followed by a stage of local causal relating, and ending with a global organizing stage, the findings from Berman and Slobin (1994) suggest that both global and local structure are equally difficult for preschool age children to narrate. However, local and global structure defined by Berman and Slobin (1994) cannot be explicitly compared due to differences in measurement. For example, connections within narrative are defined and categorized differently for the two types of structures.

Trabasso and Nickels (1992) investigated distance by classifying connections in terms of within and between episodes. They found that all individuals produced more 
within episode connections than between episode connections and that the proportion steadily increased with age. Although between episodes connections increased with age, within episode connections increased more rapidly. This suggests that all individuals use more within episode connections in general and continue to do so over time. However, the number of within episode and between episode connections was calculated based on GAO episodes produced during narration. The production of such episodes is limited in very young children (Trabasso \& Nickels, 1992), which may explain the low numbers of those connections found in their narratives. It is not clear from previous research whether the development of causal understanding in discourse is also evidenced by the use of causal connections over increasing distance.

In order to investigate the role of narrative distance in the early causal understanding, the current study employs two measures of causal distance. One measure defines within and between connections in terms of scenes that are based on boundaries inherent in the wordless picture books. This is a more accurate assessment of the distance of children's connections because it does not rely on other aspects of narrative production (i.e., the production of GAO clusters). Another measure of causal distance is the number of story ideas from antecedent to consequence per connection, independent of book scenes (see Figure 2). No study has examined narrative distance using a continuous measure. It is expected that, in the current study, younger children compared to older children narrate connections over shorter distances.

\section{Narrative Context}

The ability to produce causal connections during narrative tasks may be influenced by the narrative context. Several studies show that context has a diverse set of 
definitions and influences the structure of children's narratives. Berman (2004), for example, describes three types of elicitation methods for narratives and posits that they share developmental patterns and paths. However, the relationship between the developmental paths is not perfect and child performance may depend on the cognitive demands of the method employed (Berman, 2004; 1995). For example, preschool children found narratives from unfamiliar scripts (e.g., "What happens when people quarrel?") difficult to organize, but could temporally organize narratives for familiar scripts (e.g., doctor's visit) and personal experiences (Berman, 2004).

Berman (1995) lists familiarity and episodic complexity as contextual factors that influence children's narrative structure. Younger children tell better narratives in familiar situations and for familiar scripts. Children ages 3 to 9 almost always successfully produce narratives for scenarios that can be treated as single episodes compared to those that consist of multiple episodes. For example, narratives elicited from picture-sequences and wordless picture books were temporally sequenced, but single pictures were described in isolation. This suggests that, in general, stories based on Frog, Where are You? may be more difficult for young children.

A study by Pearce (2003) contradicts the conclusions made by Berman (1995). The study found that 5-year-old children told longer and more complex stories to accompany a wordless picture book than to a single scene picture (Pearce, 2003). Children narrated more goal-oriented stories, complex episodes, embedded episodes, and interactive episodes for the wordless picture book. More descriptive, fragmented, and abbreviated episodes were narrated for single scene pictures. Previous research, therefore, 
offers little consensus on how to define context complexity and its role in children's production of narratives.

In the study of the use of causal connections during narrative, Trabasso et al. (1992) define the complexity of the narrative context based on the complexity of goals present in books used in storytelling procedures. Trabasso et al. (1992) showed that the presence of a physical goal object increased goal identification by 4-year-olds while its absence reduced goal identification. Research has shown that the story goals are important for causal inferences, which result the production of causal connections (Trabasso \& Wiley, 2005; Wenner, 2004; Trabasso et al., 1989; van den Broek, 1989; van den Broek \& Trabasso, 1986). Therefore, the presence of a physical goal object may influence children's ability to identify the goal as well as their ability to make causal connections based on the goal. Trabasso et al. (1992) also found that the proportion of attempts with purposes was higher when the goal object was present in most of the pictures (.53; A Boy, a Dog, and a Frog) compared to when it is mostly absent (.17; Frog, Where are You?). It appears as if the repeated appearance of a goal object facilitated the identification of the book's goal. This confirms the position that goal identification supports the production of causal connections.

The current study extends the definition of goal complexity proposed in Trabasso et al. (1992) by categorizing three wordless picture books on two dimensions. The first dimension identifies whether the goal is a physical object or is abstract whereas the second dimension identifies whether the goal is mostly present (explicit) or absent (implicit) throughout the pages of the book. Books with both an abstract and implicit goal can be considered complex. Preschool children may be less likely to identify these goals 
compared to less complex goals. As a result, children may have difficulty making connections that relate complex goals to subordinate goals, actions, states, etc.

\section{Attention and Causal Understanding}

Little research has made an attempt to explain the mechanisms underlying the development of causal understanding. Some researchers propose that narrative or grammatical knowledge is necessary (Berman \& Slobin, 1994; Trabasso et al., 1992; Trabasso \& Nickels, 1992). Trabasso and Wiley (2005) state that the ability to produce causally coherent narratives requires "the use of knowledge of human goals, goal plans, their related actions, and the outcomes that affect goal success or failure" (p. 130). However, this explanation is simply an interpretation of differences between age groups and is based on little empirical evidence.

Attention skills have been implicated in the comprehension of causal information in narratives and this research also extends to the use of causal connections in narrative. Trabasso and Stein (1994) proposed that the ability to make goal plans and inferences require working memory.

The child who narrates events needs to attend to and maintain the current event in working memory; to activate and retrieve prior knowledge relevant to the events, either in general or from earlier parts of the story, in order to interpret and explain the current event; and to integrate these interpretations into a context within a plan, all within the limitations of knowledge and working memory (p. 327). Tannock, Purvis, and Schachar (1993) showed poorer recall of narratives for children diagnosed with ADHD compared to nonreferred children. Renz et al. (2003) compared the Frog, Where are You? narratives of 9- to 11-year-old boys with ADHD to those of 
nonreferred children. Boys with ADHD were less likely than comparison boys to narrate the completion of the overall goal when first telling the story, but not during the second telling. They also produced fewer goal-based attempts during both narrations, but there was a trend towards similar performance between groups. The results indicate that attentional deficits may inhibit children's ability to produce causal connections, but that children with attentional deficits can improve with repeat performance or practice. Therefore, attentional abilities may have a greater influence on initial narrative performance compared to subsequent performance.

Milich and Lorch (1994) developed and employed a television methodology in order to compare the comprehension of causal connections of children with ADHD and nonreferred children. Participants watched television during both a no-distracter and distracter condition and answered questions following each viewing. In one study, Lorch, Sanchez et al. (1999) found no significant differences in recall between the ADHD and comparison groups of children. The study did show that causal structure aided the recall of 4- to 7-year-old children, but had less of an effect on the recall of those with ADHD. Specifically, the number of causal connections in a story was a stronger predictor of comparison children's recall. Further analysis showed that causal structure was equally influential for both groups in the no-distracter condition, but not in the distracter condition. Similarly, Lorch, Diener et al. (1999) showed that causal structure aided recall in 7- to 11-year old children. Lorch, O'Neil et al. (2004) replicated these results using aurally presented narratives. These studies, like Lorch, Sanchez et al. (1999), found that children with ADHD benefited less from causal structure than the comparison group. 
Responses to factual and causal comprehension questions were also compared among the groups. Sanchez et al. (1999) found that 4- to 6-year-old comparison children performed better than children with ADHD on causal questions during both conditions. Later studies showed that comparison children performed better than those with ADHD on causal questions only during the distracter condition (Lorch, Eastham et al., 2004; Lorch et al., 2000) and the two groups of children did not differ on factual questions. Differences in causal comprehension disappeared when visual attention was taken into account (Lorch et al., 2000); time spent in long looks (i.e., looks $>15$ s; attentional inertia) mediated differences in causal comprehension (Lorch, Eastham et al., 2004). Children with attentional deficits can perform at typical levels when they can allocate their attention similarly to comparison children. Studies by Lorch and colleagues (Lorch, Eastham et al., 2004; Renz et al., 2003; Lorch et al., 2000; Lorch, Diener et al., 1999; Lorch, Sanchez et al., 1999) suggest that attention skills are important for causal understanding across a range of ages.

\section{Individual Differences in Attention and Causal Connections}

Although the research with children diagnosed with ADHD provides insight into the influence of attention in causal understanding, it does not adequately explain the role of individual differences in normal attention on the development of causal understanding. Flory et al. (2006) did find that individual differences in sustained attention mediated group differences (between children with and without ADHD) in the narrating of outcomes and GAO sequences for Frog, Where are You? Within the current model (see Figures 1 and 3) individual differences in attention skills influence children's ability to use and comprehend causal connections. Recent brain and behavioral research has led to 
the development of the attention network tasks (Rueda et al., 2004; Berger, Jones, Rothbart \& Posner, 2000), which use reaction time and accuracy as measures of attentional ability and allow individual differences to be assessed (Burns et al., 2007; Weatherholt, Harris, Burns, \& Clement, 2006; Chang \& Burns, 2005; Mezzacappa, 2004). Three attentional abilities and their network of brain areas have been identified; orienting, alerting, and executive (Fernandez-Dugue \& Posner, 2001; Berger \& Posner, 2000).

Alerting network. The alerting network accounts for the ability to achieve and maintain alertness and is most related to the right frontal lobe, the right parietal lobe, and the locus coeruleus (Fernandez-Duque \& Posner, 2001; Posner \& Petersen, 1990). An alert state allows individuals to respond to stimuli more quickly and is thought to support orienting attention. This ability is present as early as infancy (Rueda et al., 2004). The functions of this network have been studied using trials presented at variable intervals and trials accompanied by warning tones (Rueda et al., 2004; Ruff \& Rothbart, 1996). The alerting task used in current study incorporates random trials with random occurring warning tones. This network is related to motivation orientation and the interaction of temperament and motivation (Posner \& Rothbart, 2007; Chang \& Burns, 2005).

Orienting network. The orienting network accounts for shifts in attention, which can occur either overtly or covertly (Fernandez-Duque \& Posner, 2001; Posner \& Petersen, 1990). It controls both the engagement and disengagement of attention. Orienting "helps to select areas of the visual field that should be fixated" (Posner \& Rothbart, 2007, p. 63) and the alerting network engages when sustained attention is involved. It is most associated with the superior parietal lobe, the lateral pulvinar nucleus, 
and the superior colliculus (Posner \& Rothbart, 2007; Fernandez-Duque \& Posner, 2001; Posner \& Petersen, 1990). Orienting attention is seen in children as young as 3 months (Ruff \& Rothbart, 1996; Cohen, 1972), but seems to be externally controlled (Posner \& Rothbart, 2007; Ruff \& Rothbart, 1996; Cohen, 1972). That is, orienting responses are heavily influenced by the external properties of the stimulus object (DeLoache, Rissman, \& Cohen, 1978; Cohen, 1972). Internal control of orienting attention marks the emergence of inhibitory abilities (Ruff \& Rothbart, 1996) and the executive attention network (Posner \& Rothbart, 2007).

In order to study orienting attention, research often employs paradigms in which a cue precedes a target stimulus (Posner \& Rothbart, 2007; Berger et al., 2000). The superior parietal lobe shows increased activation when orienting after a cue (Posner \& Rothbart, 2007). Studies show that individuals respond rapidly to a target location if the location is preceded by a cue (Posner \& Rothbart, 2007; Berger et al., 2000). Response time decreases when individuals are cued to a location different from the target stimulus location. The temporal parietal junction is especially active during trials with cue-target incongruence (Posner \& Rothbart, 2007). The current study employs an orienting task that includes cues to stimulus location and cues to the opposite location.

The behavioral effects of orienting attention are similar for adults and children as young as 4 months, which suggests the involvement of similar brain areas across the lifespan (Posner \& Rothbart, 2007). Preschool performance on orienting tasks is related to effortful control, motivation orientation, and the interaction between temperament and motivation (Chang \& Burns, 2005). 
Executive network. The executive network manages goal directed behavior, planning, target detection, conflict resolution, task switching, the inhibition of automatic responses, and the allocation of attentional recourses (Fernandez-Duque \& Posner, 2001; Posner \& Petersen, 1990). In addition to regulating cognition, this network is also involved in the regulation of emotions (Posner \& Rothbart, 2007). Generally, the executive network is associated with the anterior cingulate gyrus, the supplementary motor area, the orbitofrontal cortex, the dorsolateral prefrontal cortex, and portions of the basal ganglia and thalamus (Fernandez-Duque \& Posner, 2001; Posner \& Petersen, 1990). The ventral area of the anterior cingulate may be related to emotion regulation whereas the dorsal area may be related to cognition regulation (Posner \& Rothbart, 2007).

The executive attention network is involved in the detection and resolution of conflict, the detection of error, and the production of novel ideas (Posner \& Rothbart, 2007). Thus, tasks involving these skills may be used to measure differences in this network. Conflict tasks, such as the Stroop task, require one to suppress a dominant response and execute a less dominant response (Posner \& Rothbart, 2007). Research employing conflict tasks with children show that the executive attention network begins to develop around age 2 and dramatic improvements appear during age 3 and between ages 4 and 7 (Posner \& Rothbart, 2007; Rueda, Rothbart et al., 2005; Rueda et al., 2004; Gerardi-Caulton, 2000). Although reaction time for such tasks decreases steadily from age 4 to adulthood, Posner and Rothbart (2007) propose that abilities associated with the executive network remain fairly stable after age 7 (Rueda et al., 2004). The current study 
uses a spatial conflict task designed by Berger et al. (2000), which is appropriate for children as young as 2-years-old (Posner \& Rothbart, 2007; Gerardi-Caulton, 2000).

Previous research shows that this network, as measured by a spatial conflict task, is related to effortful control (Chang \& Burns, 2005; Rueda, Posner, \& Rothbart, 2005; Gerardi-Caulton, 2000), analogical reasoning and IQ (Posner \& Rothbart, 2007; Weatherholt et al., 2006; Rueda, Rothbart et al., 2005), and reading achievement (Burns et al., 2007). This research and similar research on causal connections (van den Broek et al., 2000; Rizella \& O’Brien, 1996; van den Broek \& Trabasso, 1986; Trabasso \& van den Broek, 1985) indicate that the executive network may important for the development of causal understanding.

\section{Summary}

Two experiments describe individual differences in the use of causal connections by preschoolers as well as factors that may influence those individual differences. The first experiment examines these differences according to age, types of causal connections, distance of connections, and goal complexity. Previous research describes age-related differences in some attributes of causal use, but disregards individual differences (e.g., Trabasso \& Nickels, 1992). The second experiment examines the relation among individual differences in attention and individual differences in the use of causal connections. Research on ADHD suggests relations between the two skills in that children diagnosed with attentional deficits show poorer use of causal connections during narration and comprehension (e.g., Lorch, Sanchez et al., 1999; Lorch, Eastham et al., 2004). Experiment 2 tests the hypothesis that attention, as defined by the attention network model of attention, can explain some of the differences in causal understanding. 
Figure 3 depicts a model that includes the hypothesized influences on early causal understanding. The model (see Figure 3) includes both child factors (e.g., age and attention skills) and factors inherent in narrative tasks (e.g., context, complexity of causal connections, and distance of causal connections). 


\section{EXPERIMENT 1}

\section{Describing the Use of Causal Connections in Young Children}

The ability of young children (e.g. 3- to 5-year-olds) to use causal connections in narrative is assessed through elicitation methods in which children create or narrate stories that accompany wordless picture books or short picture sequences. Books by Mercer Mayer, specifically Frog, Where are You? (Mayer, 1969), are the most widely used and accepted stimuli (see Renz et al., 2003; Berman \& Slobin, 1994; Trabasso et al., 1992; Trabasso \& Nickels, 1992). Comprehension of aurally presented narratives is also used to assess causal understanding, particularly in older children (Lorch, Eastham et al., 2004; Lorch et al., 2000). The current study uses a storytelling elicitation method to offer a more in-depth examination of individual differences and factors that influence the early stages in the development of causality understanding. In addition to the influence of age, the study describes individual differences in the complexity and distance of the causal connections that preschool children produce and how goal complexity influences those aspects of narrative production (see Figure 3). The following hypotheses are examined in a preschool sample because the early stages of development in the use causal connections are reported to begin around ages 3 and 4 (Trabasso et al., 1992; Trabasso \& Nickels, 1992). 
Hypotheses 1: Three-year-old children can produce causal connections, but not as often as 4-year-old children.

Studies regarding the use of causal connections in young children conclude that 3year-olds are not capable of producing causal connections during storytelling (Berman \& Slobin, 1994; Trabasso et al., 1992; Trabasso \& Nickels, 1992). Research on infants' use of causal relations contradicts the storytelling research and demonstrates that children under 2-years-old can use simple relations to complete tasks (Wenner \& Bauer, 1999; Travis, 1997; Bauer, 1992; Bauer \& Shore, 1987). Cohen et al. (1999), employing a habituation procedure, demonstrated that 15 -month-old children can identify the cause in a three-step causal chain and differentiate between causally and temporally ordered sequences. Research concerning the causal understanding of infants employs tasks that contain observable, physical events with a small number of actions (van den Broek, 1997). On the other hand, storytelling procedures require the complex structuring of a larger number of events. These task differences may partly explain differences in findings.

Although the infant research does not employ storytelling procedures, it implies that very young children should be able to understand and use causal connections in narrative. Therefore, the current study predicts that 3-year-olds will use causal connections when narrating stories. A closer examination of the early stages of the use of causal connections during a story narrative task will contribute to the knowledge regarding the development of causal understanding. 
Hypothesis 2: The number of complex causal connections increases with increasing age.

The definitions of four types of connections based on two criteria suggest that some causal connections are more complex than others (Trabasso et al., 1989). Enabling connections are the least complex because they satisfy only one criterion. Physical connections are of middle complexity because they satisfy both criteria. Motivational and psychological connections can be considered the most complex because they satisfy both criteria and contain information about goals and internal states. Although Trabasso and Nickels (1992) found that certain types of connections are used more frequently by individuals of all ages, their analysis of the type of connections is limited because frequencies are only report for connections that fall within GAO episodes. This analysis is dictated by the narrator's ability to produce GAO episodes, which Trabasso and Nickels (1992) also found was limited in preschool children.

The present experiment describes the pattern of causal connections across the overall narratives produced by very young children. It is expected that enabling relations will appear most often followed by physical connections and then motivational and psychological connections. Furthermore, the experiment will examine whether frequencies in the production of the types of connections change across time.

Research is unclear as to how age impacts the use of different types of connections. Trabasso and Nickels (1992), for example, showed that all types of connections increase with age. Although they provide definitions that form the basis for analyzing the complexity of connections, they do not describe whether the rate of agerelated increases differs according to connection type and only provide general description of use by preschool children. Infant research offers some evidence that 
children under age 2 understand enabling relations (Wenner \& Bauer, 1999; Travis, 1997; Bauer, 1992). Little else is known about the role of connection complexity in the development of causal understanding. The current experiment examines changes in the use of enabling, physical, motivational, and psychological connections during the early stages of causal development.

Hypothesis 3: The distance of children's causal connections increases with increasing age.

The study assesses the distance over which children make causal connections in an attempt to clarify the findings of Berman and Slobin (1994) and Trabasso and Nickels (1992). The current study uses a measure of distance that classifies connections according to two categories (i.e., within-scene and between-scene) and a continuous measure across the entire narrative, independent of category. Consistency in measurement across categories allows for the comparison of within- and between-scene connections, which was not capable in Berman and Slobin (1994). It is expected that continuous measures is more sensitive to age-related improvements and individual differences.

Hypothesis 4: The coherence of children's stories varies according to goal complexity. In order to examine the influence of goal complexity, the current study extends the technique described by Trabasso et al. (1992). The current study defines goal complexity on two dimensions. The goal of a story is first classified as to whether it contains a physical goal object or a nonphysical goal (e.g., state of mind) and then classified as explicit or implicit. A third book was added to the two used in Trabasso et al. (1992) in order to examine how an abstract goal influences the causal coherence of narratives. 
It is expected that preschool children's narrations will depend on goal complexity and that this dependence decreases with age. Previous research shows that preschool children identify goals more often when the physical goal object is present compared to when it is absent. In addition, narrations of attempts with purposes are higher when the goal object is seen in most of the pictures compared to when it is mostly absent (Trabasso et al., 1992). It is also expected that the use of causal connections in more complex contexts will increase with age. Berman (2004) proposes that older children approach narrative tasks "in a more autonomous, less context-dependent fashion than younger children" (p. 273). Thus, the influence of goal complexity should decrease with increasing age.

\section{METHOD}

The study employs a mixed design, incorporating both cross-sectional and longitudinal methods. As part of a larger study, 3- and 4-year-old children were assessed individually at their preschool at the beginning of the school year and 6 months later. This mixed design allowed for the investigation of the development of causal connection production in the same children across time.

Participants

Sixty-eight 3- and 4-year-old children were recruited from a local, private preschool. Data for 10 participants were removed from analyses due to incomplete data. Data from two participants were removed because they did not complete the initial storytelling assessment, seven were removed because they did not complete the 6-month storytelling assessment, and one was removed because of incomplete attention game data. The final sample included 58 children consisting of 27 boys (46.6\%) and 31 girls 
(53.4\%). The participants included 313 -year-olds and 27 4-yearolds. At the initial assessment, the age range was from 36 to 60 months $(M=46.81, S D=7.72)$ and at the 6month assessment, the range was 42 to 66 months $(M=53.19, S D=7.70)$.

This sample age is important because previous research indicates that causal understanding begins to develop during the preschool ages (Trabasso et al., 1992; Trabasso \& Nickels, 1992) and the current study attempts to identify factors that influence the early stages of this development. There were no restrictions according to gender or ethnic background.

\section{Materials}

The Kaufman Brief-Intelligence Test (KBIT; Kaufman \& Kaufman, 1990) was used to measure of general cognitive ability. It is an individually administered measure designed for 4-year-old children to adults. There are two subtests, the vocabulary and matrices subtests. The vocabulary subtest measures expressive vocabulary through picture naming. The matrices subtest measures analogical reasoning through the completion of picture-based analogies. The current study uses raw scores instead of standard scores because the KBIT is not standardized for children below 4-years-old. The use of raw scores is appropriate due to the small age range of the sample. In order to account for age differences in raw scores, chronological age was entered as a covariate for all analyses with KBIT.

Three different wordless picture books by Mercer Mayer were used to elicit story narratives from children, A Boy, a Dog, and a Frog (1979), Frog, Where are You? (1969), and One Frog Too Many (Mayer \& Mayer, 1977). Each book contains 24 (or 25) pictures to which the children narrated a story. The pages of each book were placed in 
binders and only one picture appeared on each page. Frog, Where are You? (Mayer, 1969 ) is commonly employed in research investigating narrative development and the use of causal connections (Renz et al., 2003; Berman \& Slobin, 1994; Trabasso et al., 1992; Trabasso \& Nickels, 1992). A Boy, a Dog, and a Frog (Mayer, 1979) was combined with Frog, Where are You? (1969) in order to investigate the influence of goal complexity on children's narratives (Trabasso \& Nickels, 1992). One Frog Too Many (Mayer \& Mayer, 1977) was added to investigate another component of goal complexity; the ability to causally connect using a book with a nonphysical goal. Goal complexity is defined below.

The books were randomly chosen for each child at each assessment point. At the initial assessment, 20 children narrated stories for A Boy, a Dog, and a Frog (Mayer, 1979), 17 children narrated for Frog, Where are You? (Mayer, 1969), and 21 narrated for One Frog Too Many (Mayer \& Mayer, 1977). At the 6-month assessment, 23 children narrated stories for A Boy, a Dog, and a Frog (Mayer, 1979), 18 children narrated for Frog, Where are You? (Mayer, 1969), and 17 narrated for One Frog Too Many (Mayer \& Mayer, 1977). Story narratives resulting from the elicitation procedure were analyzed for the production of causal connections according to CDA procedures. Table 1 lists and describes all storytelling variables produced from CDA. An advantage of analyzing story narratives is that children narrate similar sets of events that can be compared.

Procedure

Children were assessed during multiple sessions at the beginning of the school year. All assessments were individually administered. Cognitive ability, measured by the KBIT, was assessed in the first session and storytelling was assessed in the third session. 
Children's storytelling was assessed again 6 months later. For the storytelling assessment, children received a different book at each time period. Each child was given a warm-up task, in which he or she told the experimenter a story from memory. The title of the book was told to the child and the experimenter stated the following instructions.

We're going to look at a story with a lot of pictures. Later, you are going to tell me the story. First, we will just look at the pictures. Remember, we're just looking at the pictures and we're not going to talk about them.

The experimenter turned the pages as the child looked at each page. After which, the child was asked to make up a story to go along with the pictures of the book. The experimenter stated the following instructions: "Now, we will look through the story again. This time I want you to tell me the story." Children were audiotaped and the experimenter turned the pages of the book. If the child needed prompting to continue with the story, the experimenter used the prompts "What happened next?" to keep the story going, or "Good job" as an encouraging statement. All experimenter prompts and statements were recorded and transcribed.

\section{Coding Procedure}

Stories were transcribed verbatim and coded according to the causal discourse analysis (CDA) outlined in research by Trabasso and colleagues (Trabasso et al., 1989; Trabasso \& Sperry, 1985; Trabasso \& van den Broek, 1985). All transcriptions were checked by an independent transcriber. Each story narrative took approximately 60 minutes to transcribe and 30 minutes to check.

The narratives were initially coded using a procedure based on CDA. This procedure was altered considerably by the primary coder. The primary coder then visited 
one of the original authors of the coding system and was trained in CDA. A new protocol was established that included minor changes to CDA. The changes did not influence the identification of causal connections, but subordinate goals, accompanying outcomes, and attempts were not coded for. The primary and other coders trained using empirical articles that described and employed CDA, the written protocol for coding, demonstrations, group discussions, and sample transcriptions. The sample transcriptions included narratives from two preschool-age children that did not participate in the study and a small number of narratives from the current study.

All narrative transcripts were then recoded to comply with CDA coding procedures. Each story narrative was coded independently by two coders. Each took approximately 45 to 60 minutes to code. The two coders then met to discuss the coding of each narrative until an agreement was made on all codes. Thirty percent of the narratives were coded by two other coders in order to establish reliability. Reliability coders coded each narrative independently and then met to agree on the coding.

Identifying information was not included in transcriptions of story narratives. A participant number identified the story narratives at all levels of transcribing, coding, and analyses. All coders were blind to the hypotheses of the current study. Hypotheses were developed after the collection and coding of all data.

Before coding, narratives were partitioned into story nodes, which are defined as statements that may consist of a subject and predicate. Clauses, a statement that includes a subject and predicate, were not used due to 3- and 4-year-old children's limited language abilities. Story nodes can account for missing subjects often present in young children's language as well as allowing for the parsing of complex clauses. For example, 
a child might say "Went looking for the frog" instead of "The boy went looking for the frog." Using story nodes allows both the former statement and complete clauses to be included in analyses. The number of story nodes was calculated for each narrative. Causal connections, distance of connections, story outcome, and experimenter prompts were coded based on the CDA, which is outlined below (see Figure 1 and Table 1).

Causal connections. Causal connections were identified and classified according to two criteria, necessity and sufficiency (Trabasso \& Sperry, 1985; Trabasso \& van den Broek, 1985). The necessity criterion applies the counterfactual argument, "If not $A$ then not B." This criterion implies that the consequence is dependent on the cause. The sufficiency criterion is more specific in that it is used to determine whether $A$ is sufficient to cause $B$. All casual connections, however, do not need to fulfill both the sufficiency and necessity criteria. Enabling relations, for example, do not satisfy the sufficiency criterion (Trabasso \& van den Broek, 1985).

Previous research shows that four types of connections appear in narratives, enabling, physical, motivational, and psychological (Trabasso \& Nickels, 1992; Trabasso et al., 1989). In all types of connections $A$ should occur temporally prior to $B$. A connection is considered motivational if $A$ contains goal information. If $A$ does not contain goal information and $B$ contains an internal state or reaction, the connection is considered psychological. If $A$ and $B$ do not contain goal information or an internal state, the connection is considered physical. In physical, motivational, and psychological connections $A$ is both necessary and sufficient for $B$. If $A$ is not sufficient for $B$, then it is an enabling connection. The number of each type of connection can be calculated for each participant. 
Overall goal and outcome. Each narrative was coded for whether it included an overall goal and outcome. The overall goal should state the central theme of the narrative. The outcome should resolve or conclude the actions, events, emotion, etc. mentioned in the overall goal. Goals and outcomes were each coded as 1 if present in the story narrative and 0 if not present.

Overall coherence. A measure of overall coherence was derived by dividing the number of story nodes used in causal connections by the total number of story nodes present in the stories. Story nodes used in causal connections included both antecedent and consequence nodes. Story nodes used in more than one connection were only counted once. Thus, overall coherence is defined as the proportion of connected story nodes.

Narrative distance. Narrative distance was measured using three variables, causal distance and within- and between-scene connections. Causal distance, partly based on Trabasso et al. (1989), is a continuous variable defined as the average number of story nodes from antecedent to consequence in each participant's narrative. For example, Figure 2 shows that two story nodes are crossed to connect $\# 2$ and $\# 4$ and five are crossed to connect $\# 4$ and $\# 9$. Raw causal distance was calculated by summing all story nodes between the antecedent and consequence story nodes for all causal connections. For the final measure of causal distance, the sum was divided by the total number of causal connections.

As another measure of distance, causal connections were categorized according to scene categories. Each book was divided into scenes. A new scene was defined as a change of scenery and/or a change of action in the story. Within-scene connections occur 
within the scene partitions whereas the between-scene connections occur across the partitions. A total was tallied for each category of connections.

Goal complexity. Before coding the children's narratives, the goal or overall theme of each book was identified by the investigator and partly based on Trabasso et al. (1992). Each book's complexity was classified based on the complexity of the goal. Goal complexity was based on two dimensions. One dimension identified whether the goal object was physical or nonphysical and the other dimension identified whether it was mostly present (explicit) or absent (implicit) throughout the book.

In A Boy, a Dog, and a Frog the boy and the dog want to catch the frog. This goal is physical (i.e., frog) and present in 22 of the 25 pictures. Therefore, it is referred to as a physical and explicit (PE) book. In Frog, Where are You? the boy wants to find the frog that ran away. This goal is physical (i.e., frog), but is only present in 5 of the 24 pictures. The book was classified as physical/implicit (PI). In One Frog Too Many the goal is to get the big frog to like and accept the new little frog. It is a nonphysical goal, since there is no actual object, and is implicit (NI). Alternative goals, however, that depend on a child's topic choice were possible and would be classified according to the two dimensions. None of the children, however, produced a goal different from the preidentified goals.

Goal complexity was dummy coded for analyses as recommended by Cohen, Cohen, West, and Aiken (2003). Since there are three levels, this resulted in g-1 or 2 new variables. Frog, Where are You? (PI) served as the reference group because it is the wordless picture book most often used in previous research. Narratives based on the PI 
book were coded as 00 , narratives for the PE book were coded as 10 , and narratives for the NI book were coded as 01 .

Experimenter prompts. Experimenter prompts were defined as statements intended to keep the child engaged and participating in the tasks and were coded after the child began narrating (not before). Prompts included statements such as "What happened next?" as well as encouraging statements such as "Good job.” Experimenter prompts were totaled for each participant's narrative.

Reliability analyses.

Reliability analyses were performed to assess the reliability of the CDA procedure. Little is known about the reliability of storytelling procedures used to identify causal connections in children's narratives. Trabasso et al. (1992) does report percentage agreement for the classification of goal plans by two independent coders. Agreement ranged from $72 \%$ to $100 \%$ depending on the category. The current study uses intra-rater correlations as measures of reliability for the coding of causal connections (Shrout \& Fleiss, 1979). Reliability analyses were performed for the total number of connections produced, types of causal connections, raw distance of causal connections, between- and within-scene connections, and number of connected story nodes. Thirty percent of narratives were randomly chosen and coded by two independent coders. Reliability for the four causal connections was done separately. A new sub sample of $30 \%$ the narratives were chosen after the total number of causal connections was identified. Disagreements were discussed until an agreement was made. Average inter-rater correlations for multiple raters are reported in Table 2 . 


\section{RESULTS}

Analyses for experiment 1 were performed in order to determine the effect of age and goal complexity on various measures of children's use of causal connections during storytelling. First, preliminary analyses were performed in order to identify possible confounds. Second, variables were transformed in order to aid analyses and reduce analyses problems. Hypotheses were then tested, which are accompanied by power analyses (Faul \& Erdfelder, 1992).

Preliminary Analyses.

Two potential confounds were examined, cognitive ability and gender. KBIT raw scores ranged from 7 to 36 for vocabulary $(M=18.17, S D=5.58)$ and from 0 to 22 for matrices $(M=10.66, S D=4.12)$. Four-year-old children had significantly higher raw scores on vocabulary, $t(56)=54.23, p<.001$, and matrices, $t(56)=54.23, p<.001$, than 3-year-olds. A multivariate analysis of variance (MANOVA) was used to examine a relation between cognitive ability and storytelling. The storytelling variables were entered as the dependent variables, the KBIT vocabulary and matrices raw scores were entered as independent variables, and chronological age was entered as a covariate (in order to account for the use of KBIT raw scores). The multivariate F-tests for the initial and 6-month assessment was not significant for either measure of cognitive ability. Cognitive ability was not considered in subsequent analyses as a control variable.

Differences on the storytelling variables according to gender were examined by conducting separate MANOVAs for the initial and 6-month assessments. Means for all storytelling variables are reported in Table 3 for the entire sample and according to 
gender. The multivariate F-tests were not significant and gender will not be controlled in subsequent analyses.

Variable Manipulation and Analysis Interpretation

Analyses for hypothesis 1 tested whether the 3-year-old subgroup could produce a degree of coherence when narrating and whether 4-year-old children produce more coherent stories. Analyses for the research questions examined differences in the number of the different types of causal connections that were produced and if the pattern of production remain consistent across time.

Hypotheses 2 through 4 examined whether chronological age and goal complexity predict individual differences in the use of causal connections using multiple regression analyses and adding variables in subsequent steps of the models. For these analyses, chronological age was centered and goal complexity was dummy coded. Cohen et al. (2003) state that centering chronological age is necessary for interpreting interactions in multiple regression analyses with indicators that have no real zero (see also Aiken \& West, 1991). To center chronological age, the mean sample age in months (46.81) was subtracted from the chronological age of individual participants. Thus, a regression coefficient of 0 corresponds to the mean age, a negative value represents an age below the mean, and a positive value represents an age above the mean. Centering also reduces unnecessary multicollinearity between predictors.

Cohen et al. (2003) and Aiken and West (1991) also recommend that categorical variables should be dummy coded for use in regression analyses. This created two new variables for goal complexity. The PI book served as the reference group. Participants 
that narrated to the PI book were coded as 0 0. Narratives for the PE book were coded as 10 and were coded as 01 for the NI book.

Such dummy coding requires unique interpretation of correlations and regression coefficients and interactions. Correlation analyses of dummy coded variables and other variables yield point-biserial correlations. This is different from a Pearson correlation in that it should be interpreted as the correlation between one book versus the other books and the other variable; for example, the correlation between PE versus other books and total connections. A correlation is not computed for the PI group because it is the reference group and coded as 00 . In order to determine the correlation for the reference group, the goal complexity variables were recoded and correlation analyses were rerun to use the NI group as the reference group (see Cohen et al., 2003). This yielded a correlation for PI versus other books.

For regression coefficients of dummy coded goal complexity variables, the interpretation requires a more extensive explanation. The general regression equation with all dependent variables entered is $\mathrm{Y}=\mathrm{B}_{1} \mathrm{PE}+\mathrm{B}_{2} \mathrm{NI}+\mathrm{B}_{3} \mathrm{~A}+\mathrm{B}_{4}(\mathrm{PE} x \mathrm{~A})+\mathrm{B}_{5}(\mathrm{NI} x$ A) $+\mathrm{B}_{0}$, where A stands for chronological age. For narratives to the PI goal (the reference goal), where $\mathrm{PE}$ and $\mathrm{NI}$ equal 0 , the equation is reduced to $\mathrm{Y}=\mathrm{B}_{3} \mathrm{~A}+\mathrm{B}_{0}$. Thus, the slope for PI narratives is $\mathrm{B}_{3}$. For narratives to the $\mathrm{PE}$ goal, where $\mathrm{PE}=1$ and $\mathrm{NI}=0$, the equation is $\mathrm{Y}=\left(\mathrm{B}_{1}+\mathrm{B}_{0}\right)+\left(\mathrm{B}_{3}+\mathrm{B}_{4}\right) \mathrm{A}$. The slope becomes $\mathrm{B}_{3}+\mathrm{B}_{4}$ and the distance between PI and the other narratives is $\mathrm{B}_{1}+\mathrm{B}_{0}$. The equation for NI narratives is reduced to $\mathrm{Y}=\left(\mathrm{B}_{2}+\mathrm{B}_{0}\right)+\left(\mathrm{B}_{3}+\mathrm{B}_{5}\right) \mathrm{A}, \mathrm{B}_{3}+\mathrm{B}_{5}$ is the slope, $\mathrm{B}_{2}+\mathrm{B}_{0}$ is the distance between PI and the other narratives (Cohen et al., 2003; Aiken \& West, 1991). Since these variables can only take on values of 1 and 0 , the corresponding coefficients represent the difference or 
distance between groups on the predicted variable. Significant coefficients for the age by goal complexity variables suggest an overall difference between the slopes for the three categories of goals. Post hoc probing is necessary, however, to determine whether the individual slopes are each significantly different from zero. To do this, regression analyses were rerun using each goal complexity group as a reference group. This makes the tests of each group's slope the test of $B_{3}$, when all variables are included in the analysis.

Hypotheses 1: Three-year-old children can produce causal connections, but not as often as 4-year-old children.

According to infant research (Wenner \& Bauer, 1999; Travis, 1997; Bauer, 1992; Bauer \& Shore, 1987), it is expected the 3-year-old children will produce some degree of causal coherence during storytelling. It is also expected that 4-year-olds will produce story narratives with more causal coherence than 3-year-olds. Means and standard deviations are reported according to age group in Table 4 for all the storytelling variables from the initial assessment.

Hotelling's $\mathrm{T}^{2}$ was performed with 3-year-old children's storytelling performance at the initial assessment as the dependent variables. The specific dependent variables were total connections, overall goal, outcome, and overall coherence. A power analysis was performed a priori for the effect size of 1 . For the current sample, the power to detect differences was greater than .99 . The multivariate test indicated that means were significantly greater than 0 , Wilk's $\Lambda=.26, F(4,27)=19.1, p<.001$. Univariate tests show that means for three of variables were significantly greater than 0 ; total connections, $F(1,30)=48.05$, overall goal, $F(1,30)=16.5$, and overall coherence, $F(1$, 
$30)=68.54, p s \leq .001$. The mean for outcome, however, was not significantly greater than 0 . These results indicate that 3-year-old children were able to produce causal connections.

In order to determine whether 3-year-old children narrated causal connections less consistently than 4-year-old children, Hotelling's $\mathrm{T}^{2}$ analyses compared 3- and 4-year-old performance at the initial assessment. A power analysis for the effect size of 1 found the power to detect differences was greater than .99 . There were no significant differences between the age groups in overall coherence and the productions of total connections, an overall goal, and an outcome. Therefore, the study cannot reliably conclude that 3-yearold children use causal connections less consistently than 4-year-old children.

Hypothesis 2: The number of complex causal connections increases with increasing age.

One goal of the current study was (1) to determine which causal connections 3and 4-year-old children produce more and least often, (2) to describe how the frequencies and pattern of frequencies change over time, and (3) to examine the influence of age on the productions of four types of causal connections. Based on previous storytelling research (Trabasso \& Nickels, 1992; Trabasso, et al., 1992; 1989), it was expected that children's use of motivational and psychological connections will improve as children get older. Nevertheless, the use of lesser complex connections may also improve during the early stages of causal development.

Trabasso and Nickels (1992) found that some connection types are used more often, but their analysis was limited to those connections produced within GAO episodes. A repeated measures MANOVA was performed in order to assess the use of causal connections by preschool children throughout entire story narratives. The four types of 
causal connections and assessment time were the dependent variables and within-subjects factors. A power analysis was performed a priori. Power was greater than .99 indicating that the current sample contained sufficient power to detect within-subject differences. There was a main effect of connection type, Wilk's $\Lambda=.21, F(3,55)=70.21, p<.001$, and assessment time, Wilk's $\Lambda=.89, F(1,57)=7.08, p=.01$ (see Figure 4). There was not a significant connection type by assessment time interaction. Contrasts performed post hoc showed that children produced more enabling connections than physical, motivational, and psychological connections, $F(1,57)=159.53, p<.001$. Children also produced significantly more physical connections than motivational and psychological connections, $F(1,57)=99.63, p<.001$, and more psychological than motivational connections, $F(1,57)=30.01, p=.009$. These results show that children rely more on the least complex type of causal connections and less on the more complex connections.

As shown by the significant main effect of assessment time, children increased in the production of all types of connections at the 6-month assessment. There was not a significant connection type by time interaction, however. This indicates that, although children increased in their use of the four types of connections, the pattern of frequencies remained consistent across the six months.

The production of the four types of causal connections by preschool children was further examined using correlation and multiple regression analyses. The goal was to determine the relation among chronological age and the four types of causal connections. Analyses were performed separately for the initial assessment and 6-month assessment. Initial assessment. Chronological age was positively correlated with two types of connections, physical and psychological (see Table 5). Children used more physical and 
psychological connections when narrating as they got older. Chronological age was not significantly correlated with enabling and motivational connections. Multiple regression analyses were performed to determine whether age predicted children's use of specific types of causal connections.

A MANOVA was first performed in order to control the type 1 error rate, reduce the number of dependent variables, and subsequently, the number of analyses (Cohen et al., 2003). All variables for the initial assessment were entered. The independent variables, which were chronological age and goal complexity, were entered as covariates. For this hypothesis, regression analyses were then performed on dependent variables that showed significant relations to chronological age in the MANOVA. Significance was judged at the .05 level. There was a significant main effect for chronological age, Wilk's $\Lambda=.54, F(11,44)=3.42, p=.002$. In univariate tests, physical, $F(1,54)=6.85, p=.011$, and psychological connections related to age, $F(1,54)=10.63, p=.002$. Enabling and motivational connections did not significantly relate to age.

Multiple regression analyses performed with chronological age entered in step 1 had a power of .79 and .65 (effect sizes $\left[f^{2}\right]=.13$ and .09 , respectively) for the current sample size. Chronological age significantly predicted physical, $F(1,56)=7.59, p=.008$, and psychological connections, $F(1,56)=5.26, p=.026$ (see Table 6). Chronological age accounted for $12 \%$ of the variance in the production of physical connections and $9 \%$ of the variance in the production of psychological connections. The analyses show that chronological age can account for a significant amount of individual differences in the use of certain connection types. Similar analyses were performed for the 6-month assessment. 
Six-month assessment. Analyses for the 6-month assessment examined relations among age and improvements in the use of the four types of causal connections. Correlation analyses for the 6-month assessment controlled for performance at the initial assessment. There were no significant correlations among chronological age and types of connections at the 6-month assessment (see Table 5). There was not a significant main effect of chronological age in the MANOVA. As a result, regression analyses were not performed for this assessment point.

Hypothesis 3: The distance of children's causal connections increases with increasing age.

Although previous research is clear on the relation among age and connection type, it is unclear as to the relation among age and the distance of causal connections. Trabasso and Nickels (1992) suggests that the use of causal connections within and between episodes increases with age. However, this research is limited by the use of episodes based on goal-attempt-outcome sequences. The measures of distance in Berman and Slobin (1994) could not be compared to one another due to differences in measurement. The current study measures the use of causal connections produced within and between scenes by calculating the number of causal connections produced within and across scene boundaries. Distance is also measured continuously as the average number of story nodes from antecedent to consequence in each participant's narrative. It is predicted that age will relate to the distance over which children produce causal connections and that a continuous measure of distance will be more sensitive. The analyses used in hypothesis 3 that were used in hypothesis 2 . Again, analyses are performed separately for the initial and 6-month assessments. 
Initial assessment. Distance was measured by three variables, within-scene connections, between-scene connections, and causal distance. Chronological age was significantly correlated with within-scene connections and between-scene connections, but not with causal distance (see Table 5). Children produced more within- and betweenscene connections with increasing age. In the MANOVA there was a significant main effect of chronological age (see hypothesis 2). Univariate tests were significant for within-scene, $F(1,54)=5.46, p=.023$, and between-scene connections, $F(1,54)=5.95$, $p=.018$, but not causal distance.

As in the multiple regression analyses described in hypothesis 2, chronological age was entered in step 1. A priori power analyses show that the current sample size was sufficient for detecting significant differences and had a power of .70 and $.82\left(f^{2}=.11\right.$ and .15). Chronological age significantly predicted within-scene, $F(1,56)=6.25, p=.015$, and between-scene connections, $F(1,56)=8.10, p<.006$ (see Table 7). Chronological age accounted for $10 \%$ of the variance in within-scene connections and $13 \%$ of the variance in between-scene connections. These results show that, for some measures of distance, increases in age can account for some of the individual differences in the distance over which children produce causal connections. The study confirms research by Trabasso and Nickels (1992), which shows that the use of both local and global causal connections increases with age.

Six-month assessment. Analyses for the 6-month assessment examined relations among age and improvements in the distance of the causal connections that children produced. Correlation analyses for the 6-month assessment controlled for initial performance. Chronological age was not significantly correlated with distance. The 
MANOVA did not show a significant main effect for chronological age. Regression analyses were not performed for the 6-month assessment.

Hypothesis 4: The coherence of children's stories varies according to goal complexity.

The current study's goal was to explain individual differences in preschooler's use of causal connections. The context in which narrative occurs has been suggested by previous research (Berman, 2004; Trabasso \& Nickels, 1992; Trabasso, et al., 1992) as one possible influence on individual differences. It was expected that the individual differences in the coherence of children's story narratives can be explained by the complexity of a story's goal in addition to chronological age.

Initial assessment. Correlation analyses controlled for chronological age (see Table 8). PE versus the other books was significantly correlated with enabling, motivational, and psychological connections. These correlations indicate that compared to the other books, narrations to the PE book were less likely to include enabling and motivational connections, but more likely to include psychological connections. NI versus the other books was significantly correlated with motivational and between-scene connections. Thus, narratives for the NI book were likely to include more motivational and between-scene connections. Narratives to the PI book were significantly correlated with psychological connections. This suggests that these narratives are less likely to include psychological connections.

Multiple regression analyses used to determine if age predicted the distance of causal connections were preceded by the MANOVA described in hypotheses 2 and 3. In the MANOVA used to reduce alpha inflation, there was a significant main effect of PE, Wilk's $\Lambda=.59, F(11,44)=2.82, p=.007$, and NI, Wilk's $\Lambda=.66, F(11,44)=2.09, p=$ 
.042. Univariate tests for PE were significant only for psychological connections, $F(1$, $54)=10.85, p=.023$. Motivational, $F(1,54)=8.79, p=.018$, and between-scene connections $F(1,54)=4.06, p=.049$, were significant for NI.

Chronological age was entered in step 1 and the goal complexity variables were added to step 2 as predictors in multiple regression analyses. Age by goal complexity interaction variables were also added in step 3 . The interaction variables were created by multiplying the goal complexity variables with chronological age.

For psychological connections, the current sample was sufficient for detecting differences at a power of .81 for goal complexity and .37 for the interaction $\left(f^{2}=.20\right.$ and .10). Goal complexity explained an additional $17 \%$ of the variance, $F(3,54)=6.03, p=$ .001 (see Table 6). Regression coefficients were significant for chronological age and PE, but not for NI. The interaction explained another $9 \%$ of the variance, $F(5,52)=5.33, p=$ .001. In this model, coefficients for PE and the age by PE interaction were significant. This suggests that the individual differences in the narration of psychological connections were significantly influenced by goal complexity (see Figure 5). Post hoc probing of the interaction showed that the slopes for the PI $(B=-0.004)$ and NI $(B=0.08)$ goals were not significantly different from zero; the slope for the PE goal $(B=0.18)$ was significant, $t(1,52)=4.04, p<.001$. Thus, age is a significant predictor of psychological connections only for the PE goal.

For motivational connections, the current sample was sufficient for detecting differences at a power of .86 for goal complexity and .37 for the interaction $\left(f^{2}=.23\right.$ and .10). Goal complexity explained an additional $19 \%$ of the variance, $F(3,54)=5.95, p=$ .001 , and the age by goal complexity interaction explained $9 \%, F(5,52)=5.20, p=.001$ 
(see Table 9). The NI and the age by NI interaction coefficients were significant. Post hoc probing of the interaction showed that the slopes for the PI $(B=-0.01)$ and PE $(B=0)$ goals were not significantly different from zero; the slope for the NI goal $(B=0.08)$ was significant, $t(1,52)=2.91, p=.005$. Age was a significant predictor of motivational connections only for narrations to the NI goal (see Figure 6).

For between-scene connections, the current sample was sufficient for detecting differences at a power .52 for goal complexity and .29 for the interaction $\left(f^{2}=.11\right.$ and .08). Goal complexity accounted for an additional $10 \%$ of the variance, $F(3,54)=5.21, p$ $=.003$. The NI coefficient was significant, which indicates that this group narrated 1.95 more between-scene connections than the other groups for the average-aged child (see Table 7). The age by goal complexity interaction did not explain an additional percentage of the variance, but produced a significant overall model, $F(5,52)=4.40, p=.002$.

The results for the initial assessment indicate that goal complexity (1) influences preschool children's production of specific types of causal connections, (2) influences the production of causal connections made across scenes, and (3) qualifies the influence of age. Similar analyses were performed for storytelling variables at the 6-month assessment.

Six-month assessment. Analyses for the 6-month assessment examined relations among goal complexity and the use of causal connections by preschool children during storytelling. Correlation analyses for the 6-month assessment controlled for chronological age and initial performance (see Table 8). The PE book compared to the other books was correlated with motivational connections, psychological connections, and overall goal. Narratives to the PE book were more likely to include psychological connections and less 
likely to include motivational connections and an overall goal. NI compared to other goals was correlated with enabling connections, motivational connections, and overall goal. NI narratives were more likely to include enabling connections, motivational connections, and an overall goal. PI versus other books was correlated with psychological connections and total story nodes. Compared to narratives from the other books, PI narratives were shorter and less likely to include psychological connections.

The MANOVA produced a significant main effects for PE, Wilk's $\Lambda=.60, F(12$, $43)=2.44, p=.016$, and NI, Wilk's $\Lambda=.64, F(12,43)=2.03, p=.045$. Univariate tests revealed that PE was significantly related to overall goal, $F(1,54)=20.76, p<.001$, and psychological connections, $F(1,54)=10.66, p=.002$. Univariate tests, however, did not indicate significant relations to NI.

For multiple regressions using the 6-month dependent variables, performance at the initial assessment and chronological age were entered in step 1, goal complexity variables in step 2, and the interaction variables in step 3. For psychological connections, the current sample was sufficient for detecting differences at a power .72 for goal complexity and .34 for the interaction $\left(f^{2}=.19\right.$ and .10$)$. Goal complexity explained $16 \%$ of the variance, $F(4,53)=3.58, \mathrm{p}=.012$ (see Table 10). Similar to analyses for the dependent variables at the initial assessment, only the PE coefficient was significant. Story narratives to PE goal contained 1.87 more physical connections than the other narratives for the average-aged child and when initial performance was held constant. The model with the interaction variables was not significant.

Logistic regression analysis was performed with overall goal as the dependent variable in order to examine the relation among children's production of an overall goal 
and goal complexity. Power analysis showed that the current sample size was sufficient for detecting differences according to goal complexity, 1- $\beta>.85$ (Hsieh, Bloch, \& Larsen, 1998). The overall model that included age, initial performance, and the goal complexity variables was significant, $\mathrm{X}^{2}(4)=30.45, p<.001$, and correctly classified $81 \%$ of the children (see Table 11 ). Wald tests showed that the coefficient was significant only for PE, which suggest that children were more likely to narrate an overall goal to the PE goal book than to the other books. The model that added the interaction variables was significant, $\mathrm{X}^{2}(6)=35.66, p<.001$, and correctly classified $82.8 \%$ of children. The coefficients for the interaction variables, however, were not significant.

The results for storytelling at the 6-month assessment show relations with goal complexity similar to the initial assessment and show that goal complexity influenced improvements across time for specific measures of children's production of causal connections.

\section{DISCUSSION}

Overall, results from the study indicate that individual differences in causal understanding within narrative can be observed in 3- and 4-year-old children. Furthermore, age and context can account for a significant percentage of the differences in how they produced causal connections during storytelling.

Three-year-old children were able to produce causal connections and overall goals and connected $38 \%$ of the nodes in their story narratives. Children this young, however, inconsistently made causal connections. For example, only $10 \%$ of 3 -year-olds narrated an outcome and while the results show that they do produce causal connections only $35 \%$ produced an overall goal and most of their story nodes remained unconnected. The 
inconsistent use of causal connections by 3-year-olds during narration is consistent with the results and conclusions made in previous studies (Berman \& Slobin, 1994; Trabasso \& Nickels, 1992; Trabasso, et al., 1992; Berman, 1988). As these studies report no evidence of causal understanding in 3-year-old children during narrative tasks, the current study shows that 3-year-old children could produce causal connections.

The frequency of specific types of connections preschool children narrated coincided with the connections' complexity level, which were consistent across time. The definitions of four types of causal connections put forth by Trabasso et al. (1989) provided a way of determining the complexity of causal connections. On average, preschool children produced more enabling connections compared to the other types of connections. This is expected because of preschool children's limited causal understanding. Physical connections appeared less often than enabling connections in narratives, but more often than psychological and motivational connections. This pattern was supported by similar results for performance sixth months later. Trabasso and Nickels (1992) also found that enabling relations occurred more often in narratives, but found that physical connections occurred less often for participants of all ages. This finding may have occurred because analyses of the types of causal connections were restricted to GAO episodes the participants produced or because of the goal complexity of the wordless-picture book used in the study. In contrast with Trabasso and Nickels (1992), which showed little difference between the production of the most complex connections, children produced more psychological than motivational connections in the current study. These results are partially supported by the overall literature, which shows that children narrate more actions than goals until 8 to 10 years (van den Broek, 1997). 
The results demonstrate that age influenced the types of connections children used and the distance over which the connections were made. The children produced more physical and psychological connections with increasing age. This confirms previous research that shows age as an important predictor of the use of causal connections in general (Berman \& Slobin, 1994; Trabasso \& Nickels, 1992; Trabasso, et al., 1992; Berman, 1988). Yet, the current study did not find that chronological age predicted children's use of enabling and motivational connections. This lack of relation may be due to low instances of motivational connections and high instances of enabling relations. Age may no longer influence the production of enabling relations during preschool age because, as suggested by research with infants, 3-year-old children have a sufficient understanding of these relations (Wenner \& Bauer, 1999; Travis, 1997; Bauer, 1992).

In terms of distance, more within- and between-scene connections were produced as children got older. The more continuous measure of causal distance was not significantly related to age. Previous research shows that both local and global connections increased with age (Berman \& Slobin, 1994; Trabasso \&Nickels, 1992). In a synthesis of the literature, van den Broek (1997) concluded that children focus more on within-episode connections until ages 6 to 8 . This conclusion is supported by age-related increases in within-scene or episode connections found in the current study and previous research. The influence of age, however, was only demonstrated for initial performance. Age did not significantly relate to improvements in the use of causal connections over time. This result may be due to practice effects, low power, or additional schooling.

The study showed that children's ability to narrate using causal connections was influenced by the narrative context. Generally, goal complexity differentially influenced 
children narrations of causal connections during initial and later storytelling performance. Goal complexity predicted the production of psychological and motivational connections, between-scene connections, and overall goals. Compared to other goals, narratives for the wordless picture book containing a physical and explicit goal were more likely to include psychological connections. This goal continued to influence children's use of psychological connections over time. The physical and explicit goal, compared to other goals, also influenced improvements in the narration of an overall goal. Narratives for this book containing a nonphysical and implicit goal were more likely to include motivational connections at the initial assessment.

Goal complexity also qualified the influence of age. As shown by a significant goal complexity by chronological age interaction, age related to increases in psychological connections only for narratives to the physical and explicit goal. In addition, age related increases in motivational and between-scene connections were only observed for the nonphysical and implicit goal. Goal complexity did not qualify the influence of age at the later assessment.

The influence of goal complexity during preschool children's online narration can be interpreted in at least two ways. Some goals may reduce cognitive load of the narrative task and facilitate the use of causal connections by preschool children in more complex ways. For example, age only predicted increases in psychological connections when the goal was physical and explicit. It is possible that the cognitive load for this goal was substantially reduced when compared to the other goals because the goal object was present in most of the pictures of the book. This is supported by a negative correlation between motivational connections and the physical and explicit goal. Another 
interpretation is that some goals may lend themselves to the use of specific type of connections. For example, a nonphysical goal may require the use of motivational connections, rather than physical and enabling connections. A goal that is not physical may be motivational or psychological. In the current study, the goal of One Frog Too Many (NI goal) is motivational; the protagonist wants the two frogs to like each other. Trabasso and Nickels (1992) found that relative frequencies of physical connections were less than other types in Frog, Where are You? narratives (PI goal). This goal may also be motivational because the boy wants to find his frog. This motivation as a story goal may increase the use of motivational and psychological relations and simultaneously reduce the use of physical relations. Both interpretations may be necessary to fully explain how children use causal connections.

Experiment 1 shows that other factors, in addition to age, influence preschool children's ability to use causal connections during storytelling. The results show that the complexity of connections, the distance over which connections need to be made, and the complexity of the narrative context work with age to influence young children's ability to narrate causally coherent narratives. These results are supported by previous research. The second experiment investigates the role of attentional processes as an additional influence on children's early causal understanding. 


\section{EXPERIMENT 2}

\section{Attentional Processes and Causal Understanding}

New findings concerning the development of attention networks may have particularly important implications for understanding attention's influence on narrative production in young children. Research shows that three networks independently relate to individual differences in math and reading achievement (Burns et al., 2007; Weatherholt et al., 2006; Chang \& Burns, 2005). For example, one study found the executive network to be related to analogical reasoning in young children living in poverty (Weatherholt et al., 2006) whereas another study found orienting and alerting to be related to motivation orientation in preschool children living in poverty (Chang \& Burns, 2005). The three specific attentional processes also each relate to a specific network of brain areas (Posner \& Rothbart, 2007; Fan et al., 2002; Fernandez-Duque \& Posner, 2001; Posner \& Petersen, 1990). Both areas of research suggest that the three attention networks will differentially relate to aspects of or precursors to casual understanding.

Computerized attention games developed by Berger et al. (2000) were used to measure individual differences in the attention networks. As depicted in the testing model of early causal understanding (see Figure 3), it is expected that the attention networks relate to children's use of causal connections during storytelling. Research shows that attention ability is related to reading (Merrell \& Tymms, 2001; de Jong, 1993; Fergusson \& Howard, 1992) and early literacy skills (Lonigan et al., 1999). Likewise, causal understanding has been shown to relate to reading and related skills (van den Broek et al., 
2000; Rizella \& O’Brien, 1996; van den Broek \& Trabasso, 1986; Trabasso \& van den Broek, 1985), which suggests an association between attention and children's understanding and use of causal connections.

The framework depicted in the current model (see Figures 3) assumes that attention skills are a prerequisite for causal understanding and that some aspects of attention are present in children prior to their ability to use causal connections. It is possible that the use of causal connections contributes to attention development. Ruff and Rothbart (1996) posit that learning is influential in attention development. In this framework, the development of causal understanding can be viewed as learning. However, research on attention networks suggests that attention develops before the ability to use causal connections (Posner \& Rothbart, 2007; Rueda et al., 2004; GerardiCaulton, 2000; Ruff \& Rothbart, 1996). Even executive attention, which develops later than the other two networks, begins to develop earlier than the use of causal connections has been demonstrated (Posner \& Rothbart, 2007; Rueda et al., 2004; Gerardi-Caulton, 2000; Ruff \& Rothbart, 1996).

Hypothesis 1: Attention networks will differentially predict measures of causal understanding.

The current study predicts that individual differences in attention, as measured by attention networks tasks, differentially relates to measures of the use of causal connections. The three attentional networks are shown to have both a degree of independence and a degree of dependence (Fan, McCandliss, Sommer, Raz, \& Posner, 2002; Fernandez-Duque \& Posner, 2001). For example, the alerting network may relate to the elicitation of experimenter prompts due to its relation to distractibility. Berman and 
Slobin (1994) suggested that unusable narratives were more frequent in 3-year-olds due to their distractibility. The orienting network, on the other hand, may influence the type of information children attend to and report in tasks of causal understanding. During the initial stages of causal understanding, children may focus attention on aspects that they find interesting and be unable to disengage from those aspects. Object labeling may be the aspect of storytelling most attended to by 3 -year-old children and their parents (Trabasso et al., 1992). The attention networks should show different patterns of relations, with some overlap, to the different measures causal connections production. Hypothesis 2: Attention networks will predict individual differences in the improvement of causal understanding across time.

It is also hypothesized that attention will predict improvements in the use of causal connections across time. Renz et al. (2003) found differences between boys with ADHD and comparison boys in the production of goal based connections during their initial narratives. Some, but not all, of the differences persisted during a second narration. Therefore, the current study investigates whether the relation between attention and the use of causal connections remains stable across time.

\section{METHOD}

The method for the second experiment incorporates attention assessments into the method described in the first experiment. Children played attention games and narrated stories during separate sessions at the beginning of the school year. Children narrated stories a second time 6-months later, but did not play the attention games. The same storytelling procedure and coding outlined in the first experiment was used. 


\section{Participants}

The sample included the same 58 3- and 4-year-old participants from the first experiment. As in the previous experiment, children were assessed at their preschool.

\section{Materials}

Materials for measuring cognitive ability and storytelling were the same as the first experiment. During all three attention games, the child sat at a child-size table in front of a computer with a touch screen. A marker was placed on the table, between the child and computer screen. The child was instructed to put his or her finger on the marker before and after each trial. A video recorder was placed behind the child, facing the computer screen in order to record responses for all trials (Berger et al., 2000).

\section{Procedure}

Storytelling and KBIT procedures were described in the first experiment. Storytelling was assessed twice during the school year whereas cognitive ability was assessed only once. As part of a larger study, both cognitive ability and attention were assessed in the first of multiple sessions.

The attention games consist of three computer tasks; each designed to measure one of three attention networks as identified by Posner and Peterson (1990; Berger et al., 2000; Chang \& Burns, 2005). Videos of the attention games were reviewed after the completion of all tasks. Trials in which the child's finger did not begin on the marker, in which the touch screen did not immediately record the child's response, and responses that were faster than $500 \mathrm{~ms}$ were eliminated from analyses. Accuracy and reaction time measures were recorded for all attention tasks. Table 12 lists the variables and their descriptions. Median reaction time (MRT) was calculated only for correct trials. 
Alerting task. The alerting task "measures change in the internal state following the presentation of a warning signal" (Berger et al., 2000, p. 298). The child was instructed to help the farmer "catch" his animals by touching the animal as fast as possible when it appeared on the screen. At the end of the game, the child was presented with a picture of all the animals back on the farm. An auditory warning signal, presented at different intervals $(200,500,1000$, and $2500 \mathrm{~ms})$ occurred in half of the trials. The task consisted of 32 trials and up to 3 practice trials.

Orienting task. This task measures spatial orientation of attention. The child was presented with two fish bowls to the left and right of a fixation point. The child was instructed to pretend that his or her finger was a worm and to "feed the fish" when it appeared in one of the bowls by touching it as fast as possible. A trial consisted of a fixation stimulus, followed by a cue, and then the fish. The cue, appearing on each bowl with equal probability, is defined by a color change in one of the fish bowls. The cue and fish could appear in either the same fish bowl (i.e. compatible trials) or opposite fish bowls (i.e. incompatible trials) during a trial. The task consisted of 32 trials and 3 practice trials.

Spatial conflict task. This task measures one aspect of executive attention, the ability to resolve a conflict. The child must resolve the conflict between the location of a stimulus and the response. Two houses were presented at the left and right bottom of the screen with a picture in each. A stimulus appeared at the top of the screen. The child was instructed to "help the picture find its home" by touching the house with the identical picture as fast as possible. A compatible trial occurred when the stimulus appeared on the same side of the screen as the house with the identical picture. In an incompatible trial, 
the stimulus appeared on the opposite side of the house with an identical picture. Compatible and incompatible trials occurred in random order for a total of 32 trials and up to 3 practice trials.

\section{RESULTS}

The goal of the second experiment was to understand how individual differences in attention abilities impact storytelling. Preliminary analyses were performed in order to identify confounding variables. Variables were then transformed according to previous research, to aid analyses, and to reduce multicollinearity. Lastly, performance on the attention games was examined for relations with storytelling at the initial and 6-month assessments.

\section{Preliminary Analyses}

There was no significant relation among cognitive ability and storytelling variables (see Experiment 1). The relation among cognitive ability and attention game performance was examined after the transformation of the attention game variables (see Variable Manipulation and Analysis Interpretation below). Gender differences in attention game performance were analyzed using a separate MANOVA. Means are reported in Table 13 according to gender. Results showed no significant gender effect for the attention or storytelling variables (see Experiment 1). Gender will not be considered in subsequent analyses.

Correlation analyses were performed to determine whether the reaction times for the attention games were correlated with each other. Accuracy was not used because child performance on attention networks tasks is often very high and accuracy is less sensitive than reaction time (Weatherholt et al., 2006; Mezzacappa, 2004). Table 14 
shows that attention game MRTs were also significantly related to each other and chronological age. Such correlations were moderate to high and pose problems due to multicollinearity in regression analyses. Chronological age was included in subsequent analyses as a control variable due to its relation to storytelling, attention game performance, and cognitive ability.

\section{Variable Manipulation and Analysis Interpretation}

The attention variables were transformed using a linear transformation described by Gerardi-Caulton (2000) in order to reduce multicollinearity, decrease the number of variables entered for analyses, and retain the information measured by compatible and compatible trials and trials with and without a warning stimulus. A priming measure was calculated for the alerting task by taking the difference in MRT for trials preceded by the warning stimulus and for trials not preceded by the stimulus and dividing by the MRT for stimulus-preceded trials. Positive scores indicate that it took children longer to make correct responses to No-Beep trials than to Beep trials. An interference measure was calculated for the orienting task by taking the difference in MRT between incompatible trials and compatible trials and dividing by the MRT for compatible trials (GerardiCaulton, 2000). The same method was used to calculate an interference measure for the spatial conflict task. For both the orienting and spatial conflict tasks, negative scores indicate that the children made correct responses to compatible trials faster than to incompatible trials, which is consisted with previous research (Posner \& Rothbart, 2007; Berger et al., 2000). The transformed attention variables were not significantly correlated with each other, therefore, eliminating the problem of multicollinearity. 
In order to determine if cognitive ability related to attention, a MANOVA was performed with the transformed attention game variables as dependent variables, KBIT scores as independent variables, and chronological age as a covariate. There was a significant main effect for KBIT vocabulary, Wilk's $\Lambda=.00, F(51,21.65)=2.22, p=$ .023. Univariate tests showed that it was significant for the alert priming score, $F(17,9)=$ $4.34, p=.015$, and the spatial conflict interference score, $F(17,9)=3.11, p=.044$. Therefore, only KBIT vocabulary raw scores were controlled in subsequent analyses. As described in the first experiment and in Cohen et al. (2003), all continuous variables used in subsequent analyses were centered. For Experiment 2, the continuous variables include chronological age, the alert priming measure, and the orienting and spatial conflict interference measures.

Hypothesis 1: Attention networks will differentially predict measures of causal understanding.

The goal of the first hypothesis was to determine how individual differences in attention influence individual differences in the coherence of children's story narratives. Based on research with children with ADHD (Flory et al., 2006; Renz et al., 2003), it is expected that individual differences in attention relate to children's use of causal connections during storytelling. Attention networks research (Fan et al., 2002; Fernandez-Duque \& Posner, 2001) would suggest that different attentional abilities relate to different aspects of early narrative causal understanding.

Correlation analyses that controlled for chronological age and KBIT vocabulary were performed (see Table 15). The alert priming measure was correlated with causal distance; the orienting interference score was correlated with total connections, physical 
connections, between-scene causal connections, and overall goal; and the spatial conflict interference score was correlated with prompts. These correlations indicate that children's use of causal connections increased as performance on attention games increased.

Multiple regression analyses were performed with the storytelling variables as the dependent variables. As in the first experiment, a MANOVA was first performed in order to control type 1 error. All the dependent variables for the initial assessment and chronological age, KBIT vocabulary, and attention game variables were entered as covariates. Regression analyses were then performed on the dependent variables that showed significant relations to attention game measures in the MANOVAs. Significance was judged at the .05 level. There was a significant main effect only for the alert priming score, Wilk's $\Lambda=.58, F(11,42)=2.83, p=.007$. Univariate tests showed that only causal distance was significantly related to the alert priming variable, $F(1,52)=18.48, p$ $<.001$.

Multiple regression analyses were performed with causal distance as the dependent variable. Chronological age and KBIT vocabulary was entered in step 1 and the three transformed attention variables were entered in step 2. Power analysis show that the sample size was sufficient for detecting differences at a power of $.97\left(f^{2}=.39\right)$. Attention game performance accounted for $28 \%$ of the variance in causal distance, $F(5$, $52)=4.95, p=.001$ (see Table 16). The coefficients for chronological age and alert priming were significant. The negative coefficient for the alert priming scores suggests that children with faster MRT narrated connections over greater distances. Individual 
differences in distance over which children narrated causal connections was predicted by individual differences in alerting attention.

Hypothesis 2: Attention networks will predict individual differences in the improvement of causal understanding across time.

The aim of the second hypothesis was to determine the relation among individual differences in attention and improvements in the use of causal connections during storytelling. Correlation analyses for the second hypothesis controlled for chronological age, KBIT vocabulary, and initial performance (see Table 17). The analyses produced no significant correlations. There was not a significant main effect for any attention game variable in the MANOVA for the 6-month assessment. As a result, regression analyses were not performed on any of the 6-month dependent variables.

\section{DISCUSSION}

Previous research posits that increases in causal understanding are due to increases in narrative knowledge. Trabasso and colleagues (Trabasso \& Wiley, 2005; Trabasso, 1994; Trabasso \& Stein, 1994; Trabasso et al. 1992; Trabasso \& Nickels, 1992) and Berman and colleagues (Berman, 1995; Berman \& Slobin, 1994) conclude that 3year-old children lack knowledge of prior events from earlier in the story and about events in general; knowledge of human goals and related actions and outcomes; and knowledge relevant to grammar. These conclusions, however, lack empirical evidence. The current study is one of the first to examine the role of individual differences in attention on children's causal understanding within discourse.

Children's ability to stay alert or to maintain a state of arousal predicted the distance of their causal connections. Thus, children with higher alerting skills made 
causal connections over longer distances. More consistency in attention allowed children to make causal connections that crossed multiple story statements or ideas. Key to creating coherence in story narratives is the ability to make both local and global connections, with global connections requiring one to cross multiple story statements during narration. Studies of the attention networks most often find that the orienting and executive attention networks relate to child outcomes (Posner \& Rothbart, 2007; Weatherholt et al., 2006; Chang \& Burns, 2005; Rueda, Posner et al., 2005; Rueda, Rothbart et al., 2005; Gerardi-Caulton, 2000). Few studies have found alertness to be related to child outcomes. Burns et al. (2007) found that increases in performance on the alerting attention task predicted increases in math achievement after controlling for cognitive ability in 4- to 6-year-old children. Chang and Burns (2005) found the alert attention network to be related to children's motivation orientation. Previous studies and the current study indicate that alertness, as measured by the attention networks, is important for child outcomes that are important for school readiness and achievement.

Flory et al. (2006) showed that sustained attention mediated differences between 7- to 9-year-old children with ADHD and comparison children in story narratives on several measures of coherence. The researchers note that the ability to sustain an alert state was not evident in the observable behavior of children with ADHD and that children were able to complete the storytelling task. In both the current study and Flory et al. (2006) alertness is a cognitive measure of "depth of concentration or depth of information processing” (p. 862), which influences children's ability to narrate using causal connections. Lorch, Milich, Astrin, and Berthiaume (2006) measured 6- to 11-year-old children's cognitive engagement while they watched television and found that increased 
engagement related to better recall of the television program. Recall and cognitive engagement was highest for causally connected content.

Specific to the current study, the depth of cognitive engagement predicted individual differences in the distance of the causal connections that children produced, but did not predict other aspects of narrative causal understanding. Differences in encoding may explain how increases in alerting attention relate to increases in the distance of causal connections. Children with lower alerting skills may encode enough information to narrate a story with some aspects of causal coherence, but not enough to use causality over longer distances. Children with higher alerting skills may be able to encode more information over a longer time and, thus, connect content over a longer distance. This is supported by research showing that 4- to 10-year-old children's cognitive engagement increased as the causally connected information continued to be presented (Lorch et al., 2006). This increase in cognitive engagement occurred at all ages, even for preschool children, but did not occur in children with ADHD. Lorch et al. (2006) conclude that changes in cognitive engagement lead individuals to build a coherent narrative representation during the narrative task. Children with lower skills in alerting attention may not build a narrative representation that includes information that is causally connected over long distances compared to children with higher skills in alerting attention.

The current study also found that children's orienting ability was related to the total number of connections they produced, the number of physical and between-scene connections they produced, and their production of an overall goal. Children with better attention-shifting skills produced more connections overall, more physical and between- 
scene connections, and were more likely to produce an overall goal. Blair and Razza (2007) found attention shifting to be related to both the literacy and math achievement of children. Lastly, executive attention abilities were related to the number of experimenter prompts children elicited. This indicates that children with higher executive attention needed less prompting to narrate stories or to complete the storytelling task.

Measures of attention did not significantly relate to changes over time in children's ability to use causal connections for story narration. Similarly, Renz et al. (2003) showed that children with ADHD began to causally connect story narratives in the same way as the comparison group during the second narration of Frog, Where are You? Combined, these results may suggest that the effect of individual differences in attention skills may be mediated by practice. The lack of significant difference between the attention variables and other storytelling variables may be due to limitations of the study. Limitations due to low power and the use of community sample are further discussed below.

The findings from the second experiment highlight four important points regarding the study of early causal understanding and attention. Increases in knowledge may not sufficiently explain differences in early causal understanding. The ability to maintain an alert cognitive state is relevant to children's ability to produce causal connections. As a result, individual differences in alerting attention may also explain some of the individual differences in children's ability to use causal connections for comprehension and recall. The finding that only alerting attention predicted the distance of children's connections during storytelling, that orienting attention related to other aspects of storytelling performance, and that executive attention related to the number of 
prompts elicited during the task provides further support for the idea that attention networks independently relate to skills (Fan et al., 2002; Fernandez-Duque \& Posner, 2001). That is, the attention networks differentially related to aspects of preschooler's storytelling.

Lastly, the results from the current study combined with findings from previous research (Burns et al., 2007; Flory et al., 2006) indicate that the study of attention networks in children has important implications for understanding factors that influence early causal understanding and, thus, school readiness and achievement. The relation among individual differences in attention and school-related skills impacts children's performance over time. Blair and Razza (2007) show that attentional skills measured in preschool and kindergarten relate to achievement in kindergarten. 


\section{CONCLUSION}

Findings of the current study indicate that young children's use of causal connections and the role of child and narrative-related factors are more complicated than proposed by previous research. Previous research simply concludes that preschool children rarely or inconsistently use causality in narrations, which is due to their lack of narrative or event knowledge (Berman \& Slobin, 1994; Trabasso, 1994; Trabasso et al. 1992; Trabasso \& Nickels, 1992). This study indicates that preschool children's causal understanding is also complex.

There are implications for interpreting previous research that examines early causal understanding in light of the current study. For example, the current study and previous research (e.g., Berman \& Slobin, 1994) suggest that narrative distance impacts children's ability to use causal connections. Low and Durkin (1998) investigated children's ability to narrate canonical television programs that are temporally predictable compared to noncanonical programs that deviate from a predictable script (e.g., incorporate twists or dreams). Younger children (first and third graders) showed a lower proportion of causal connections when narrating noncanonical programs compared to when narrating a canonical program. The researchers concluded that the results showed an early dependence on event knowledge or temporal relations because younger children were more affected by changes in structure. Noncanonical narratives, however, may require children to understand causal connections over longer distances than canonical narratives. Thus, age differences found by Low and Durkin (1998) may be explained by 
older children's ability to use and understand causal connections over greater distances. Moreover, the current study and Flory et al. (2006) find that measures of causal distance are influenced by children's ability to maintain an alert state, an attentional skill that develops with age.

The influence of context found in the current study supplies another possible explanation for the differences in the infant research and narrative research. Differences in the task complexity or task demands may explain the findings that children under age 3 can understand causal connections in certain conditions, but understand very little causality in narrative (e.g., van den Broek, 1997). On the other hand, the current study suggests that 3-year-old children use causal connections in narrative and other research shows that they are better able to use causality in certain narrative conditions (Berman, 1995). The present study provides an initial investigation into the role of narrative context while providing a catalyst for similar studies in the future.

The current study also contributes to the overall knowledge of the development of causal understanding. Results inform what influences both children's use and understanding of causal connections in discourse. This knowledge is important due to its relationship to narrative ability and to memory and comprehension tasks. Narrative is found in all forms and functions of language such as literary, historical, social and personal texts (Trabasso, 1994), and television (Lorch, Diener et al., 1999; Lorch, Sanchez et al., 1999). It can serve to socialize and organize experience as well as communicate the past to others (Trabasso, 1994). This pervasiveness makes the ability to understand and produce narrative important for social and academic success. This is confirmed by research showing that the understanding of causal connections is important 
for comprehension and recall in a variety of narrative forms (Lorch, Diener et al., 1999;

Lorch, Sanchez et al., 1999; Wolman et al., 1997; Rizella \& O'Brien, 1996; van den Broek et al., 1996; van den Broek, 1989; van den Broek \& Trabasso, 1986; Trabasso et al., 1984; Trabasso \& van den Broek, 1985).

However, more investigations into the role attention plays as well as the interaction between causal understanding and other abilities are needed in order to fully understand early causal understanding and narrative ability. Research indicates that one must incorporate a variety of skills for narrative production and comprehension. Such skills include the ability to use grammar (John, Lui, \& Tannock, 2003), referential language (Wigglesworth, 1997), and linguistic devices (Shapiro \& Hudson, 1997). Further investigations into the role of social skills such as theory of mind (Pelletier \& Astington, 2004) and the understanding of emotion or mental states (Eaton, Collis, \& Lewis, 1999) are also a needed. The current study offers an initial examination in to the influence of attentional processes in processing the demands of narrative in addition to causal understanding.

\section{Limitations}

One limitation of the current study involves the use of the production of causal connections as a measure of early causal understanding. Elicitation methods may underestimate children's actual understanding. If this is true, what information is learned from the relation of attention and causal connections used in storytelling is limited.

Trabasso and Rodkin (1994) propose that what a speaker says may underestimate what he or she actually knows and encodes. For example, when 4-year-old children were prompted by descriptive and explanatory questions, statements of attempts and purposes 
significantly increased (Trabasso et al., 1992). However, several studies show that the ability to produce causal connections (Renz et al., 2003; Trabasso et al., 1992; Trabasso \& Nickels, 1992) follows a developmental trend similar to the recall of causal information (Berman, 2004; Lorch, Diener et al., 1999; Lorch, Sanchez et al., 1999; van den Broek et al., 1996). The developmental trends are also similar across mediums; story narratives and television (Lorch \& Sanchez, 1997). For example, 4-year-old children recall information that is causally connected more often than unconnected information, but less consistently than older children and adults (van den Broek et al., 1996). This pattern is identical to that described in the storytelling research. Four-year-olds use causal connections during storytelling, but do so less reliably than older children and adults (Trabasso \& Nickels, 1992; Trabasso, et al., 1992). Furthermore, Flory et al. (2006) argue that the use of online narration or storytelling reduces the demand on memory. As a result, the use of storytelling by the current study is age-appropriate and allows some conclusions to be made about the causal understanding of preschool children based on the findings.

Another limitation of the study is the coding procedure used to identify causal connections in children's narratives. Although the CDA has been used in several studies of child and adult connection use (e.g., van den Broek et al., 1996; van den Broek \& Trabasso, 1986), there is no standardized procedure for analyzing the relations found in narratives. This lack of standardization has led to the use of different coding procedures, which makes comparisons across studies difficult. Furthermore, there is a lack of information concerning the reliability of narrative coding procedures. The current study is one of the first to report reliability information on the coding of causal connections. Most 
studies employing similar coding methods find identical developmental trends across a variety of narrative forms. This consistency of findings across similar coding procedures suggests a high degree of reliability.

The study may also have limited power. For example, all independent variables could not be simultaneously included into multiple regression analyses. Cohen (1992), for example, recommends sample sizes of 107 to 757 in order to detect medium to small effect sizes at $\alpha=.05$ for a large number of independent variables. The current study, therefore, employed separate analyses in order to investigate the impact of goal complexity and individual differences in attention on children's use of causally connections. Low power in some of the analyses may also explain some of the nonsignificant results. For example, individual differences in attention did not explain a significant proportion of the variance in changes over time in the use of causal connections. Correlation analyses showed small effect sizes when cognitive ability and previous performance was held constant. Future research with larger samples can detect smaller effects and investigate the combined influence of attention, context, as well as other variables on children's narrative production. The study describes how these factors independently influence individual differences in early causal understanding, is one of the first to explain such influences, and contributes to future research. Lastly, the use of a community sample limits the present study in at least two ways. Recruiting the entire sample from one private preschool may have resulted in a largely homogenous sample. For example, individual differences may have been smaller than those of a more diverse sample. This is directly related to the power of the statistical analyses used in the study. 


\section{Potential Implications}

Besides the implications for explanations of early causal understanding, results from the current study provide further evidence concerning the role attention may play in development of school readiness skills. This work extends the attention literature to factors that can impact overall narrative comprehension, reasoning, and decision making. Previous research shows that the understanding of causal connections is important for aurally presented narratives (Lorch, Diener et al., 1999; Lorch, Sanchez et al., 1999; Wolman et al., 1997; van den Broek et al., 1996; van den Broek, 1989; Trabasso, Secco, \& van den Broek, 1984). Attention may also play a role in children's general comprehension of discourse through its influence on early causal understanding (see Figure 3). In addition, Schulz and Gopnik (2004) demonstrated that 3- to 5-year-old children's ability to use and make inferences is needed during decision-making tasks. Inferences are the basis for causal connections (Trabasso, 1994) and the ability to use causal relations may aid reasoning and decision making. Thus, knowledge about the role of attention in understanding causal inferences has implications for reasoning and decision making skills.

Results from the current study and previous research suggest that both causal understanding and attention skills can serve as targets for interventions aimed at improving school readiness skills in very young children. Preliminary research shows that children's executive attention can be improved through special video games (Posner \& Rothbart, 2007; Rueda, Rothbart et al., 2005). Such improvements are evidenced by decreases in reaction time on attention tasks and changes in brain activity, which relate to improvements in IQ and analogy. Training attention may, therefore, have beneficial 
effects for causal understanding. In turn, improvements in causal understanding may lead to increases in skills related to discourse as well as a range of academic skills (e.g., Peterson, Jesso, \& McCabe, 1999; Wolman et al., 1997).

Such attention and causal understanding interventions may be especially useful for improving the academic outcomes of children at-risk due to poverty. Children in poverty tend to have lower attention skills than their more advantaged peers (Mezzacappa, 2004), which contributes to lower academic achievement (Breznitz \& Norman, 1998; de Jong, 1993; Fergusson \& Horwood, 1992). A recent study by Blair and Razza (2007) shows that the attentional skills of children living in poverty impact their math and literacy achievement. Such interventions will be useful for other populations of children with problems of attention and low academic achievement, such as children born prematurely (Davis, Burns, Snyder, Dossett, \& Wilkerson, 2004; Davis \& Burns, 2001). The results from the current study and studies with children diagnosed with ADHD (Flory et al., 2006; Lorch et al., 2006; Lorch, Eastham et al., 2004; Lorch, O’Neil et al., 2004; Lorch et al., 2000; Lorch, Diener et al., 1999; Lorch, Sanchez et al., 1999) offer preliminary investigations into new targets for unique interventions for unique populations of children.

Before interventions can be developed, research is needed in at least two areas in addition to those identified in the current study's model (see Figure 1). Research is needed on other possible influences on early causal understanding. For example, some research suggests that parents contribute to children's use of causal connections through conversations (Peterson \& McCabe, 1997), elicitation techniques (Peterson \& McCabe, 1994), and storytelling (Harkins, Koch, \& Michel, 1994). Peterson, Jesso, and McCabe 
(1999) implemented an intervention that encouraged parents to behave in ways that encouraged narrative discourse with their children, such as frequently talking about past experiences and asking "wh" questions. Following the intervention, it was found that children in the intervention group produced longer and more complicated narratives. Children's home environment, experiences with reading and other forms of narrative, and motivation (Burns, Brown, \& Harris, 2007) may also influence their causal understanding. Some studies also suggest that early language skills such as those assessed by IQ measures relate to causal understanding (Lile, Brown, Richard, \& Burns, 2007; Flory et al., 2006). The current study, however, did not find a relation among IQ and the use of causal connections during storytelling. Similarly, Wolman et al., (1997) found that differences between children with mild mental retardation, with learning disabilities, and without disabilities in the use of causal structure for recall could not be explained by differences in IQ. It is, therefore, unclear as to how other factors influence young children's use of causal connections.

Examinations of the interactions among factors are also needed to further explain and identify the influences on causal understanding. For example, research shows that parent's play an important role in children's development of attention skills (Brown et al., 2007; Harris, Robinson, Chang, \& Burns, 2007; Davis et al., 2004). Therefore, parent behaviors may impact early causal understanding both directly and indirectly through its affect on children's attention.

Finally, there is a need for research that examines the role of early causal understanding in the development of school readiness skills. In adults, research links causal understanding to memory, comprehension, and writing (van den Broek et al., 
2000; Rizella \& O’Brien, 1996; van den Broek et al., 1996; van den Broek \& Trabasso, 1986; Trabasso \& van den Broek, 1985). Research with school age children finds that causal understanding is related to recall and comprehension (Lorch, Diener et al., 1999; Lorch, Sanchez et al., 1999; Wolman et al., 1997; van den Broek et al., 1996; Trabasso et al., 1984) as well as later reading skills (White, van den Broek, \& Kebndeou, 2007). Research with adults and school age children provides insight into the impact of early causal understanding on school readiness, but this relation has not been studied directly. One exception is studies involving infants, which show that children under 24 months can use enabling relations to complete age-appropriate tasks (Wenner \& Bauer, 1999; Travis, 1997; Bauer, 1992), but these studies employ less complex tasks. In combination with the current study, examinations of the role of causal understanding in school readiness skills would offer insight into the overall role of causal understanding, help to explain the complex interactions among factors, and provide insight into how a variety of factors influence this understanding. 


\section{REFERENCES}

Aiken, L. S. \& West, S. G. (1991). Multiple Regression: Testing and Interpreting Interactions. Newbury Park, CA: Sage Publications.

Bauer, P. J. (1992). Holding it all together: How enabling relations facilitate young children's event recall. Cognitive Development, 7, 1-28.

Bauer, P. J. \& Shore, C. M. (1987). Making a memorable event: Effects of familiarity and organization on young children's recall of action sequences. Cognitive Development, 2, 327-338.

Berger, A., Jones, L., Rothbart, M. K., \& Posner, M. I. (2000). Computerized games to study attention in childhood. Behavior Research Methods, Instruments, \& Computers, 32(2), 297-303.

Berger, A. \& Posner, M. I. (2000). Pathologies of brain attentional networks. Neuroscience and Biobehavioral Reviews, 24, 3-5.

Berman, R. A. (1988). On the ability to relate events in narrative. Discourse Processes, 11, 469-497.

Berman, R. A. (1995). Narrative competence and storytelling performance: How children tell stories in different contexts. Journal of Narrative and Life History, 5(4), $285-$ 313.

Berman, R. A. (2004). The role of context in developing narrative abilities. In Strömqvist, S. \& Verhoeven, L. (eds.), Relating Events in Narrative: Typological and Contextual Perspectives, (pp. 261-280). Mahwah, NJ: Erlbaum. 
Berman, R. A. \& Slobin, D. I. (1994), Relating Events in Narrative: A Crosslinguistic Developmental Study, (pp. 39-84). Hillsdale, NJ: Erlbaum.

Blair, C. \& Razza, R. P. (2007). Relating effortful control, executive function, and false belief understanding to emerging math and literacy ability in kindergarten. Child Development, 78(2), 647-663.

Burns, B. M., Brown, D. D., \& Harris, R. C. (March, 2007). Motivation orientation and storytelling ability in young children. Poster presentation at the Society for Research on Child Development's Biennial Conference. Boston, MA.

Burns, B. M., Chang, F., Snyder, E., Robinson, J. B., Davis, D. W., Weatherholt, T., et al. (2007; submitted). Specific attention skills and achievement in young children of poverty. Early Education \& Development.

Breznitz, Z. \& Norman, G. (1998). Differences in concentration ability among low- and high-SES Israeli students: A follow-up study. The Journal of Genetic Psychology, 159(1), 82-93.

Brown, D. D., Harris, R. C., Davis, D. W., Robinson, J. B., Snyder, E. H., Weatherholt, T. N., et al. (2007). Attention regulation in children from low SES families: The influence of child temperament and maternal sensitivity. Symposium paper presentation at the Society for Research on Child Development's Biennial Conference. Boston, MA.

Chang, F. \& Burns, B. M. (2005). Attention in preschoolers: Associations with effortful control and motivation. Child Development, 76(1), 247-263.

Cohen, J. (1988). Statistical Power Analysis for the Behavioral Sciences. Hillsdale, NJ: Erlbaum. 
Cohen, J. (1992). A power primer. Psychological Bulletin, 112(1), 155-159.

Cohen, J., Cohen, P., West, S. G., \& Aiken, L. S. (2003). Applied Multiple Regression/Correlation Analysis for the Behavioral Sciences ( $3^{\text {rd }}$ edition). Mahwah, NJ: Erlbaum.

Cohen, L. B. (1972). Attention-getting and attention-holding processes of infant visual preferences. Child Development, 43, 869-879.

Cohen, L. B., Rundell, L. J., Spellman, B. A., \& Cashon, C. H. (1999). Infants' perception of causal chains. American Psychological Society, 10(5), 412-418.

Davis, D. W. \& Burns, B. M. (2001). Problems of self-regulation: A new way to view deficits in children born prematurely. Issues in Mental Health Nursing, 22, 305323

Davis, D. W., Burns, B. M., Snyder, E., Dossett, D., \& Wilkerson, S. (2004). A parentchild interaction and attention regulation in children born prematurely Journal for Specialists in Pediatric Nursing, 9(3), 85-94.

de Jong, P. F. (1993). The relationship between students' behavior at home and attention and achievement in elementary school. British Journal of Educational Psychology, 63, 201-213.

DeLoache, J. S., Rissman, M. W., \& Cohen, L. B. (1978). An investigation of attentiongetting process in infants. Infant Behavior and Development, 1, 11-25.

Eaton, J. H., Collis, G. M., \& Lewis, V. A. (1999). Evaluative explanations in children's narratives of a video sequence without dialogue. Journal of Child Language, 26, 699-720.

Fan, J., McCandliss, B. D., Sommer, T., Raz, A., \& Posner, M. I. (2002). Testing the 
efficiency and independence of attentional networks. Journal of Cognitive Neurosciences, 14(3), 340-347.

Faul, F. \& Erdfelder, E. (1992). GPOWER: A-priori, post-hoc, and compromise power analyses for MS-DOS [Computer program]. Bonn, FRG: Bonn University, Department of Psychology.

Fergusson, D. M. \& Horwood, L. J. (1992). Attention deficit and reading achievement. Journal of Child Psychology \& Psychiatry, 33(2), 375-385.

Fernandez-Dugue, D. \& Posner, M. I. (2001). Brain imaging of attentional networks in normal and pathological states. Journal of Clinical and Experimental Neuropsychology, 23(1), 74-93.

Flory, K., Milich, R., Lorch, E. P., Hayden, A. N., Strange, C., \& Welsh, R. (2006). Online story comprehension among children with ADHD: Which core deficits are involved? Journal of Abnormal Child Psychology, 34, 853-864.

Gerardi-Caulton, G. (2000). Sensitivity to spatial conflict and the development of selfregulation in children 24-36 months of age. Developmental Science, 3(4), 397404.

Harkins, D. A., Koch, P. E., \& Michel, G. F. (1994). Listening to maternal story telling affects narrative skill of 5-year-old children. Journal of Genetic Psychology, 155(2), 247-257.

Harris, R. C., Robinson, J. B., Chang, F., \& Burns, B. M. (2007). Characterizing preschool children's attention regulation in parent-child interactions: The roles of effortful control and motivation. Journal of Applied Developmental Psychology, $28,25-39$. 
Hsieh, F.Y., Block, D.A., \& Larsen, M.D. 1998. A simple method of sample size calculation for linear and logistic regression. Statistics in Medicine, 17, 16231634.

John, S. F., Lui, M., \& Tannock, R. (2003). Children's story retelling and comprehension using a new narrative resource. Canadian Journal of School Psychology, 18(1/2), 91-113.

Lile, J., Brown, D., Richard, H., \& Burns, B. M. (February, 2007). The relationship between early language skills and the ability to make causal connections. Poster presentation at Posters at the Capitol. Frankfort, KY.

Lonigan, C. J., Bloomfield, B. G., Anthony, J. L., Bacon, K. D., Phillips, B. M., \& Samwel, C. S. (1999). Relations among emergent literacy skills, behavior problems, and social competence in preschool children from low- and middleincome backgrounds. Topics in Early Childhood Special Education, 19(1), 40-53.

Lorch, E. P., Eastham, D., Milich, R., Lemberger, C. C., Sanchez, R. P., Welsh, R., et al. (2004). Difficulties in comprehending causal relations among children with ADHD: The role of cognitive engagement. Journal of Abnormal Psychology, 113(1), 56-63.

Lorch, E. P., Diener, M. B., Sanchez, R. P., Milich, R., Welsh, R., \& van den Broek, P. (1999). The effects of story structure on the recall of stories in children with attention deficit hyperactivity disorder. Journal of Educational Psychology, 91(2), 273-283.

Lorch, E. P., Milich, R., Astrin, C. C., \& Berthiaume, K. S. (2006). Cognitive engagement and story comprehension in typically developing children and 
children with ADHD from preschool through elementary school. Developmental Psychology, 42(6), 1206-1219.

Lorch, E. P., Milich, R., Sanchez, R. P., van den Broek, P. Baer, S., Hooks, K., et al. (2000). Comprehension of televised stories in boys with attention deficit/hyperactivity disorder and nonreferred boys. Journal of Abnormal Psychology, 109(2), 321-330.

Lorch, E. P., O’Neil, K., Berthiaume, K. S., Milich, R., Eastham, D., \& Brooks, T. (2004). Story comprehension and the impact of studying on recall in children with attention deficit hyperactivity disorder. Journal of Clinical Child and Adolescent Psychology, 33(3), 506-515.

Lorch, E. P. \& Sanchez, R. P. (1997). Children's memory for televised events. In P. W. van den Broek, P. J. Bauer, \& T. Bourg (Eds.), Developmental Spans in Event Comprehension and Representation: Bridging Fictional and Actual Events, (pp. 271-291). Mahwah, NJ: Erlbaum.

Lorch, E. P., Sanchez, R. P., van den Broek, P., Milich, R., Murphy, E. I., Lorch, R. F., et al. (1999). The relation of story structure properties to recall of television stories in young children with attention-deficit hyperactivity disorder and nonreferred peers. Journal of Abnormal Child Psychology, 27(4), 293-309.

Low, J. \& Durkin, K. (1998). Structure and causal connections in children's on-line television narratives: What develops. Cognitive Development, 13, 201-225. Mayer, M. (1969). Frog, Where are You? New York: Dial Books for Young Readers. Mayer, M. (1979) A Boy, a Dog, and a Frog. New York: Dial Books for Young Readers. Mayer, M. \& Mayer, M. (1977). One Frog Too Many. New York: Dial Books for Young 
Readers.

Merrell, C. \& Tymms, P. B. (2001). Inattention, hyperactivity and impulsiveness: Their impact on academic achievement and progress. British Journal of Educational Psychology, 71, 43-56.

Mezzacappa, E. (2004). Alerting, orienting, and executive attention: Developmental properties and sociodemographic correlates in an epidemiological sample of young, urban children. Child Development, 75(5), 1373-1386.

Milich, R. \& Lorch, E. P. (1994). Television viewing methodology to understand cognitive processing of ADHD children. Advances in Clinical Child Psychology, $16,177-201$.

Pearce, W. M. (2003). Does the choice of stimulus affect the complexity of children's oral narratives? Advances in Speech-Language Pathology, 5(2), 95-103.

Pelletier, J. \& Astington, W. (2004). Action, consciousness and theory of mind: Children's ability to coordinate story characters' actions and thoughts. Early Education and Development, 15(1), 5-22.

Peterson, C., Jesso, B., \& McCabe, A. (1999). Encouraging narratives in preschoolers: an intervention study. Journal of Child Language, 26, 49-67.

Peterson, C. \& McCabe, A. (1994). A social interactionist account of developing decontextualized narrative skill. Developmental Psychology, 30(6), 937-948.

Peterson, C. \& McCabe, A. (1997). Echoing Our Parents: Parental Influences on Children's Narration. In M.W. Pratt \& B.E. Fiese (Eds.), Family stories and the lifecourse: Across time and generations (pp. 27-54). Allyn \& Bacon.

Posner, M. I. \& Petersen, S. E. (1990). The attention system of the human brain. Annual 
Review of Neuroscience, 13, 25-42.

Posner, M. I. \& Rothbart, M. K. (2007). Educating the Human Brain. Washington, DC: American Psychological Association.

Rabiner, D., Coie, J. D., \& The Conduct Problems Prevention Research Group (2000). Early attention problems and children's reading achievement: A longitudinal investigation. Journal of the American Academy of Child \& Adolescent Psychiatry, 39(7), 859-867.

Rapport, M. D., Scanlan, S. W., \& Denney, C. B. (1999). Attention-deficit/hyperactivity disorder and scholastic achievement: model of dual developmental pathways. Journal of Child Psychology \& Psychiatry, 40(8), 1169-1183.

Renz, K., Lorch, E. P., Milich, R., Lemberger, C., Bodner, A., \& Welsh, R. (2003). Online story representation in boys with attention deficit hyperactivity disorder. Journal of Abnormal Child Psychology, 31(1), 93-104.

Rizzella, M. L. \& O’Brien (1996). Accessing global causes during reading. Journal of Experimental Psychology: Learning, Memory, and Cognition, 22(3), 1208-1218.

Rueda, M. R., Fan, J., McCandliss, B. D., Halparin, J. D., Gruber, D. B., Lecari, L. P., et al., (2004). Development of attentional networks in childhood. Neuropsycholgia, $42,1029-1040$.

Rueda, M. R., Rothbart, M. K., McCandliss, B. D., Saccomanno, L., \& Posner, M. I. (2005). Training, maturation, and genetic influences on the development of executive attention. PNAS, 102(41), 14931-14936.

Rueda, M. R., Posner, M. I., Rothbart, M. K. (2005). The development of executive attention: Contributions to the emergence of self-regulation. Developmental 
Neuropsychology, 28(2), 573-594.

Ruff, H. A. \& Rothbart, M. K. (1996). Attention in Early Development: Themes and Variations. New York: Oxford University Press.

Sanchez, R. P., Lorch, E. P., Milich, R., \& Welsh, R. (1999). Comprehension of televised stories by preschool children with ADHD. Journal of Clinical Child Psychology, 28(3), 376-385.

Schulz, L. E. \& Gopnik, A. (2004). Causal learning across domains. Developmental Psychology, 40(2), 162-176.

Shapiro, L. R. \& Hudson, J. A. (1997). Coherence and cohesion in children's stories. In Costermans, J. \& Fayol, M. (eds.), Processing Interclausal Relationships: Studies in the Production and Comprehension of Text, (pp. 23-48). Mahwah, NJ: Erlbaum.

Shrout, P. E. \& Fleiss, J. L. (1979). Intraclass correlations: Uses in assessing rater reliability. Psychological Bulletin, 86(2), 420-428.

Suh, S. \& Trabasso, T. (1993). Inferences during reading: Converging evidence from discourse analysis, talk-aloud protocols, and recognition priming. Journal of Memory and Language, 32, 279-300.

Tannock, R., Purvis, K. L., \& Schachar, R. J. (1993). Narrative abilities in children with attention deficit hyperactivity disorder and normal peers. Journal of Abnormal Child Psychology, 21(1), 103-117.

Trabasso, T. (1994). The power of the narrative. In Lehr, F. \& Osborn, J. (eds.), Reading, Language, and Literacy: Instruction for the Twenty-First Century, (pp. 187-200). Hillsdale, NJ: Erlbaum. 
Trabasso, T. \& Nickels, M. (1992). The development of goal plans of action in the narration of a picture story. Discourse Processes, 15, 249-275.

Trabasso, T. \& Rodkin, P. C. (1994). Knowledge of goal/plans: A conceptual basis for narrating Frog where are you? In Berman, R. A. \& Slobin, D. I. (eds.), Relating Events in Narrative: A Crosslinguistic Developmental Study, (pp. 85-106). Hillsdale, NJ: Erlbaum.

Trabasso, T., Secco, T., \& van den Broek, P. (1984). Causal cohesion and story coherence. In Mandl, H., Stein, N. L., \& Trabasso, T. (eds.), Learning and Comprehension of Text,

Trabasso, T. \& Sperry, L. L. (1985). Causal relatedness and importance of story events. Journal of Memory and Language, 24, 595-611.

Trabasso, T. \& Stein, N. L. (1994). Using goal-plan knowledge to merge the past with the present and the future in narrating events on line. In Haith, M. M., Benson, J. B., Roberts, R. J., \& Pennington, B. F. (eds.), The Development of Future-Oriented Process, (pp. 323-349). Chicago: University of Chicago Press.

Trabasso, T., Stein, N. L., Rodkin, P. C., Munger, M. P., \& Baughn, C. R. (1992). Knowledge of goals and plans in on-line narration of events. Cognitive Development, 7, 133-170.

Trabasso, T. \& Suh, S. (1993). Understanding text: Achieving explanatory coherence through on-line inferences and mental operations in working memory. Discourse Processes, 16, 3-34.

Trabasso, T. \& van den Broek, P. (1985). Causal thinking and the representation of narrative events. Journal of Memory and Language, 24, 612-630. 
Trabasso, T., van den Broek, P., \& Suh, S. (1989). Logical necessity and transitivity of causal relations in stories. Discourse Processes, 12, 1-25.

Trabasso, T. \& Wiley, J. (2005). Goal plans of action and inferences during comprehension of narratives. Discourse processes, 39(2\&3), 129-164.

Travis, L. L. (1997). Goal-based organization of event memory in toddlers. In P. W. van den Broek, P. J. Bauer, \& T. Bourg (Eds.), Developmental Spans in Event Comprehension and Representation: Bridging Fictional and Actual Events, (pp. 111-138). Mahwah, NJ: Erlbaum.

van den Broek, P. (1989). Causal reasoning and inference making judging the importance of story statements. Child Development, 60, 286-297.

van den Broek, P. (1997). Discovering the cement of the universe: The development of event comprehension from childhood to adulthood. In P. W. van den Broek, P. J. Bauer, \& T. Bourg (Eds.), Developmental Spans in Event Comprehension and Representation: Bridging Fictional and Actual Events, (pp. 321-342). Mahwah, NJ: Erlbaum.

van den Broek, P., Linzie, B. Fletcher, C., \& Marsolek, C. J. (2000). The role of causal discourse structure in narrative writing. Memory \& Cognition, 28(3), 711-721. van den Broek, P., Lorch, E. P., \& Thurlow, R. (1996). Children's and adults' memory for television stories: The role of causal factors, story-grammar categories, and hierarchical level. Child Development, 67, 3010-3028.

van den Broek, P. \& Trabasso, T. (1986). Causal networks versus goal hierarchies in summarizing text. Discourse Processes, 9, 1-15.

Weatherholt, T., Harris, R. C., Burns, B. M., \& Clement, C. (2006). Analysis of attention 
and analogical reasoning in children in poverty. Journal of Applied Developmental, 27(2), 125-135.

Wenner, J. A. (2004). Preschoolers' comprehension of goal structure in narratives. Memory, 12(2), 193-202.

Wenner, J. A. \& Bauer, P. J. (1999). Bringing order to the arbitrary: One- to two-yearolds' recall of event sequences. Infant Behavior and Development, 22(4), 585590.

Wigglesworth, G. (1997). Children's individual approaches to the organization of narrative. Journal of Child Language, 24, 279-309.

White, M. J., van den Broek, P. W., \& Kebndeou, P. (2007). Comprehension skills and basic language skills predict future reading ability: A cross-sequential study of young children. Symposium paper presentation at the Society for Research on Child Development's Biennial Conference. Boston, MA.

Wolman, C. (1991). Sensitivity to causal cohesion in stories by children with mild mental retardation, children with learning disabilities, and children without disabilities. Journal of Special Education, 25(2), 135-154.

Wolman, C., van den Broek, P., \& Lorch, R. F. (1997). Effects of causal structure on immediate and delayed story recall by children with mild mental retardation, children with learning disabilities, and children without disabilities. Journal of Special Education, 30(4), 439-455. 
APPENDIX

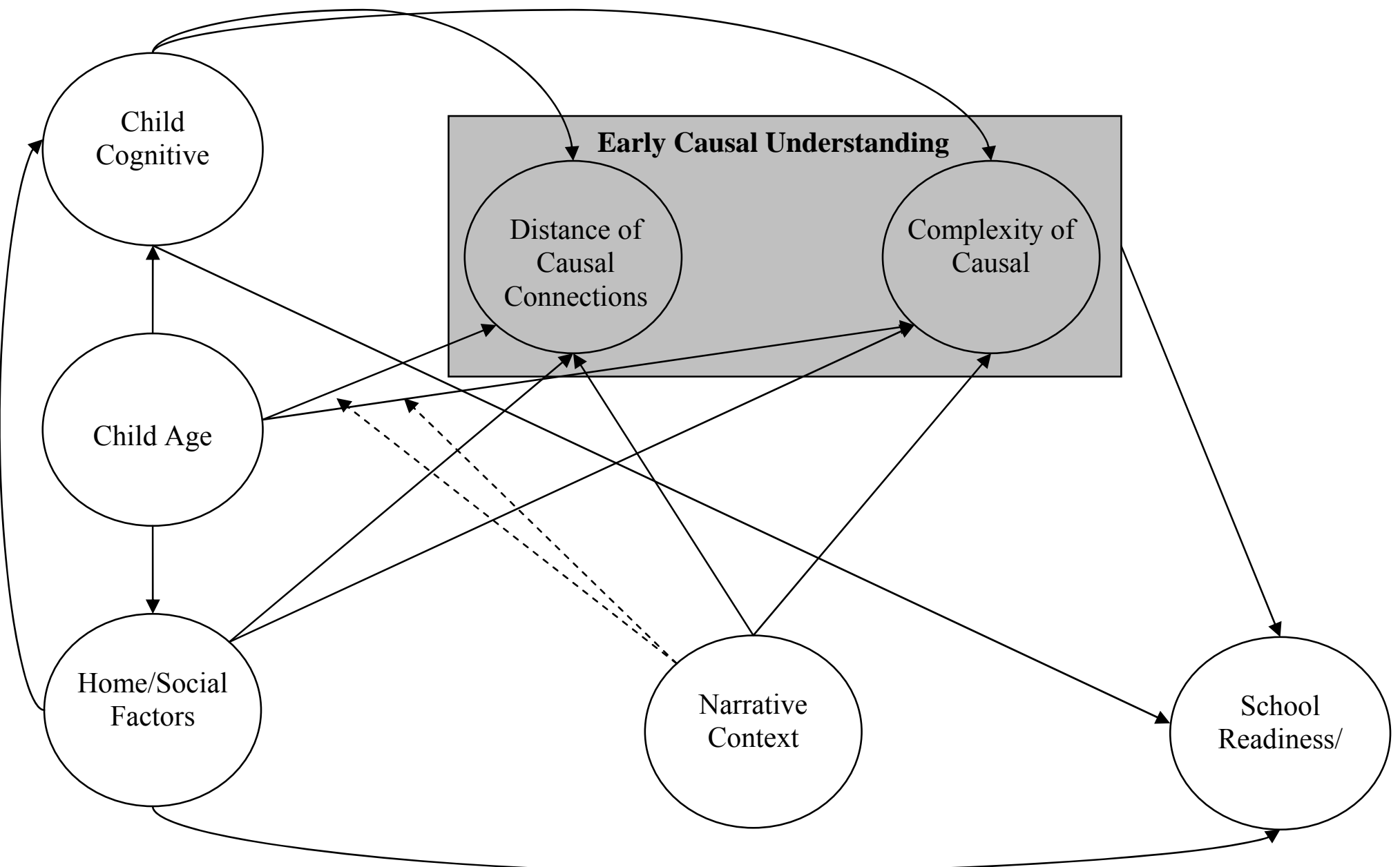

Figure 1. Conceptual Model of Early Causal Understanding in Discourse 


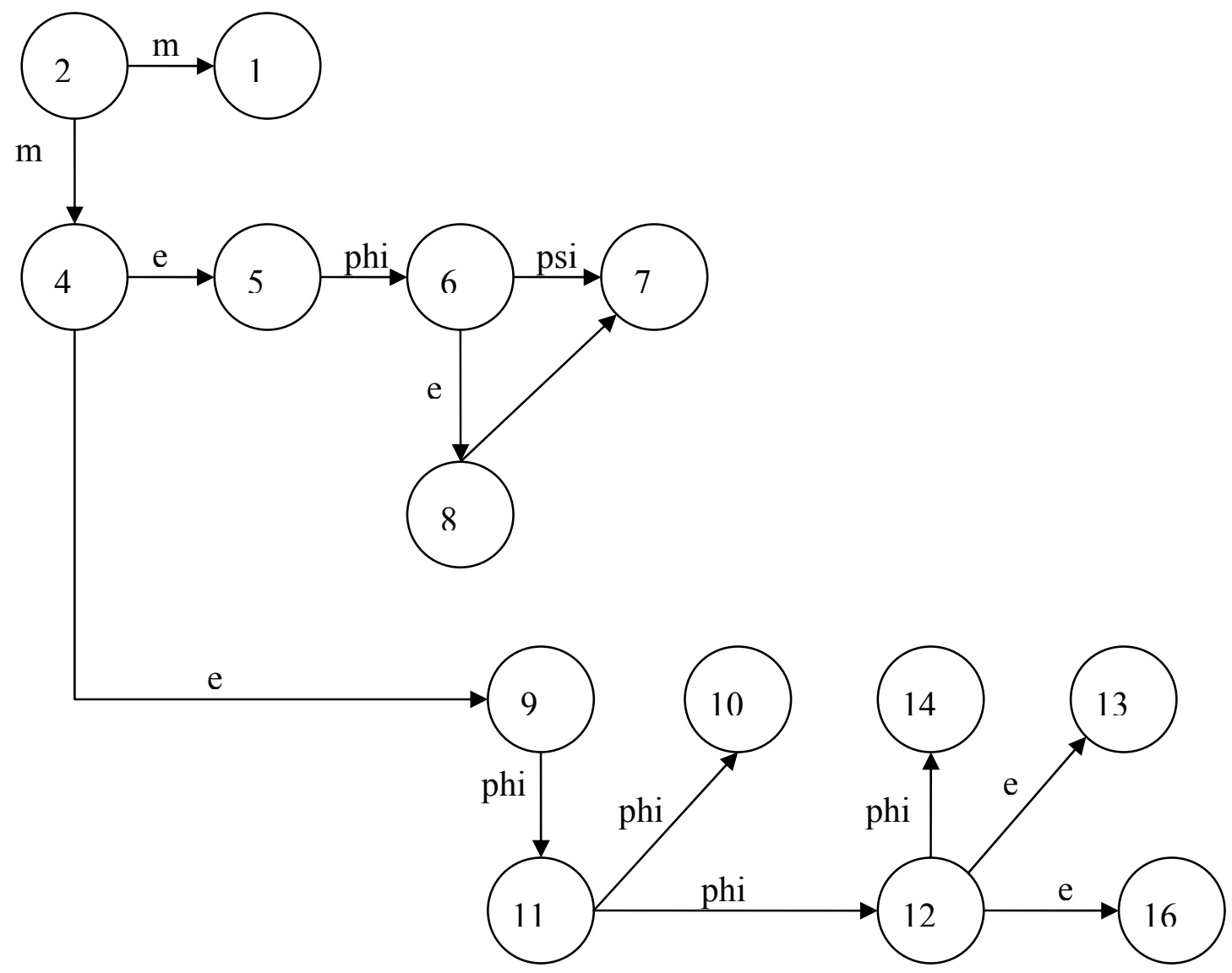

\section{Story Nodes}

1. They're walking down.

2. He's going to catch a frog

3. .... a frog.

4. The boy is gonna catch a frog.

5. The boy tripped.

6. And then the boy fell in the water.

7. Then...um...then the frog was happy

8. and the dog fell in too.
9. Then he tried to catch the frog

10. but he didn't.

11. Then he jumped onto a log.

12. Then he's going to get the net.

13. Uh oh.

14. And...um... he's going to catch the froggie.

15. Then he's going to (sound effect).

16. He's gonna slap it on the dog.

Figure 2. Causal discourse analysis of A Boy, a Dog, and a Frog. 


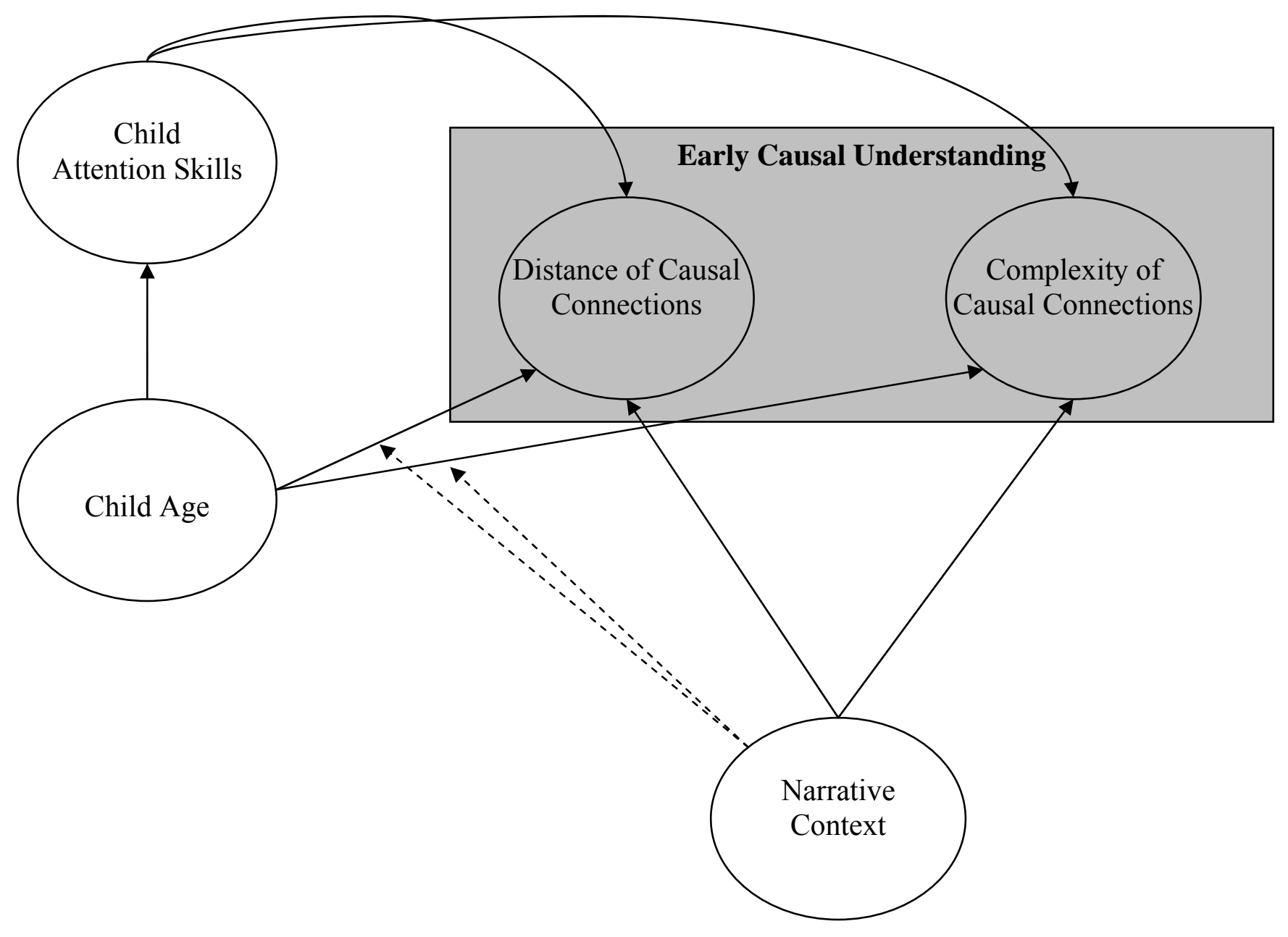

Figure 3. Testing Model of Early Causal Understanding 
Table 1

Descriptions of Storytelling Variables Measured from the Storytelling Procedure

\begin{tabular}{|c|c|}
\hline Storytelling variables & Description \\
\hline $\begin{array}{l}\text { Goal complexity } \\
\text { classification: } \mathrm{PE}, \mathrm{PI}, \mathrm{NI}\end{array}$ & $\begin{array}{l}\text { Books are classified based on the type and presence of } \\
\text { the goal object. }\end{array}$ \\
\hline Total connections & Number of all connections regardless of type \\
\hline Enabling connections & $\begin{array}{l}\text { Connections in which A is necessary for B, but not } \\
\text { sufficient. }\end{array}$ \\
\hline Physical connections & $\begin{array}{l}\text { Connections that do not contain goal information or } \\
\text { internal states; A is necessary and sufficient for B. }\end{array}$ \\
\hline Psychological connections & $\begin{array}{l}\text { Connections in which A contains no goal information } \\
\text { and B contains an internal state or reaction; A is } \\
\text { necessary and sufficient for B. }\end{array}$ \\
\hline Motivational connections & $\begin{array}{l}\text { Connections in which A contains goal information; A } \\
\text { is necessary and sufficient for B. }\end{array}$ \\
\hline Story nodes & $\begin{array}{l}\text { Number of statements that consist of a predicate and } \\
\text { sometimes a subject. }\end{array}$ \\
\hline Causal distance & $\begin{array}{l}\text { Average number of story nodes in causal connections } \\
\text { between the antecedent nodes and consequence nodes. }\end{array}$ \\
\hline Within-scene connections & Frequency of connections within one scene. \\
\hline Between-scene connections & Frequency of connections that cross scene partitions. \\
\hline Overall goal & $\begin{array}{l}\text { Central theme of the story. } 0 \text { if an overall goal is not } \\
\text { present in the child's story and } 1 \text { if it is present. }\end{array}$ \\
\hline Outcome & $\begin{array}{l}\text { Resolution of the story. } 0 \text { if an outcome is not present } \\
\text { in the child's story and } 1 \text { if it is present. }\end{array}$ \\
\hline Overall coherence & Proportion of story nodes used in causal connections. \\
\hline Experimenter prompts & Frequency of experimenter statements during the task. \\
\hline
\end{tabular}


Table 2

Intra-Correlations Measuring Reliability for Storytelling Variable

\begin{tabular}{lcc}
\hline Storytelling variables & Initial & 6-Month \\
\hline Total connections & .93 & .97 \\
Enabling connections & .85 & .98 \\
Physical connections & .86 & .79 \\
Psychological connections & .97 & .90 \\
Motivational connections & .75 & .88 \\
Raw causal distance & .85 & .81 \\
Within scene connections & .90 & .98 \\
Between scene connections & .87 & .81 \\
Number of connected nodes & .92 & .98 \\
\hline
\end{tabular}


Table 3

Storytelling Means and Standard Deviations According to Gender

\begin{tabular}{|c|c|c|c|c|c|c|}
\hline \multirow[b]{2}{*}{ Storytelling variables } & \multicolumn{3}{|c|}{ Initial assessment } & \multicolumn{3}{|c|}{ 6-month assessment } \\
\hline & Boys & Girls & Total & Boys & Girls & Total \\
\hline Total connections & $10.85(8.84)$ & $11.19(7.51)$ & $11.03(8.08)$ & $14.15(8.57)$ & $15.29(10.42)$ & $14.76(9.54)$ \\
\hline Enabling connections & $5.79(4.29)$ & $6.48(3.98)$ & $6.16(4.11)$ & $8.15(6.30)$ & $7.87(6.04)$ & $8.00(6.11)$ \\
\hline Physical connections & $3.96(3.75)$ & $3.29(3.28)$ & $3.60(3.49)$ & $4.33(3.13)$ & $4.90(3.82)$ & $4.64(3.49)$ \\
\hline Motivational connections & $0.59(1.25)$ & $0.26(0.58)$ & $0.41(0.96)$ & $0.82(1.42)$ & $0.74(1.26)$ & $0.78(1.33)$ \\
\hline Psychological connections & $0.52(1.12)$ & $1.16(2.35)$ & $0.86(1.90)$ & $0.85(1.13)$ & $1.77(2.32)$ & $1.35(1.91)$ \\
\hline Story nodes & $29.67(4.55)$ & $32.45(14.20)$ & $31.16(10.84)$ & $31.85(6.57)$ & $35.39(12.02)$ & $33.74(9.94)$ \\
\hline Causal distance & $1.53(0.73)$ & $1.66(0.71)$ & $1.60(0.72)$ & $1.64(0.44)$ & $1.68(0.61)$ & $1.66(0.54)$ \\
\hline Within-scene connections & $7.74(6.06)$ & $7.97(4.96)$ & $7.86(5.45)$ & $10.22(6.23)$ & $11.94(8.70)$ & $11.14(7.64)$ \\
\hline Between-scene connections & $3.11(3.24)$ & $3.23(3.36)$ & $3.17(3.28)$ & $3.93(2.93)$ & $3.36(2.23)$ & $3.62(2.57)$ \\
\hline Overall goal $^{\mathrm{a}}$ & $0.48(0.51)$ & $0.45(0.51)$ & $0.47(0.50)$ & $0.74(0.45)$ & $0.45(0.51)$ & $0.59(0.50)$ \\
\hline Outcome $^{\mathrm{a}}$ & $0.15(0.36)$ & $0.23(0.43)$ & $0.19(0.40)$ & $0.48(0.51)$ & $0.45(0.51)$ & $0.47(0.50)$ \\
\hline Overall coherence & $0.45(0.26)$ & $0.48(0.29)$ & $0.47(0.27)$ & $0.53(0.23)$ & $0.53(0.24)$ & $0.53(0.23)$ \\
\hline Experimenter prompts & $11.11(8.15)$ & $8.39(6.12)$ & $9.66(7.20)$ & $5.78(5.45)$ & $5.45(5.55)$ & $5.60(5.46)$ \\
\hline
\end{tabular}

${ }^{\mathrm{a}}$ Means represent the proportion of the sample that produced the variable. 
Table 4

Storytelling Means and Standard Deviations According to Age

\begin{tabular}{|c|c|c|c|c|c|c|}
\hline \multirow[b]{2}{*}{ Storytelling variables } & \multicolumn{3}{|c|}{ Initial assessment } & \multicolumn{3}{|c|}{ 6-month assessment } \\
\hline & 3-year-olds & 4-year-olds & Total & 3-year-olds & 4-year-olds & Total \\
\hline Total connections & $8.32(6.69)$ & $14.15(8.53)$ & $11.03(8.08)$ & $13.32(9.40)$ & $16.41(9.60)$ & $14.76(9.54)$ \\
\hline Enabling connections & $5.10(3.88)$ & $7.37(4.09)$ & $6.16(4.11)$ & $7.61(5.75)$ & $8.44(6.58)$ & $8.00(6.11)$ \\
\hline Physical connections & $2.61(2.94)$ & $4.74(3.77)$ & $3.60(3.49)$ & $4.03(3.60)$ & $5.33(3.29)$ & $4.64(3.49)$ \\
\hline Motivational connections & $0.19(0.48)$ & $0.67(1.27)$ & $0.41(0.96)$ & $0.58(0.99)$ & $1.00(1.62)$ & $0.78(1.33)$ \\
\hline Psychological connections & $0.42(1.18)$ & $1.37(2.40)$ & $0.86(1.90)$ & $1.10(1.47)$ & $1.63(2.31)$ & $1.35(1.91)$ \\
\hline Story nodes & $29.74(7.36)$ & $32.78(13.79)$ & $31.16(10.84)$ & $34.10(9.05)$ & $33.33(11.04)$ & $33.74(9.94)$ \\
\hline Causal distance & $1.56(0.81)$ & $1.65(0.60)$ & $1.60(0.72)$ & $1.56(0.58)$ & $1.77(0.47)$ & $1.66(0.54)$ \\
\hline Within-scene connections & $6.16(4.78)$ & $9.81(5.57)$ & $7.86(5.45)$ & $10.48(7.45)$ & $11.89(7.91)$ & $11.14(7.64)$ \\
\hline Between-scene connections & $2.16(2.53)$ & $4.33(3.68)$ & $3.17(3.28)$ & $2.87(2.50)$ & $4.48(2.42)$ & $3.62(2.57)$ \\
\hline Overall goal & $0.35(0.49)$ & $0.59(0.50)$ & $0.47(0.50)$ & $0.55(0.51)$ & $0.63(0.49)$ & $0.59(0.50)$ \\
\hline Outcome & $0.10(0.30)$ & $0.30(0.47)$ & $0.19(0.40)$ & $0.35(0.49)$ & $0.59(0.50)$ & $0.47(0.50)$ \\
\hline Overall coherence & $0.38(0.26)$ & $0.56(0.26)$ & $0.47(0.27)$ & $0.47(0.24)$ & $0.60(0.21)$ & $0.53(0.23)$ \\
\hline Experimenter prompts & $11.77(7.55)$ & $7.22(6.04)$ & $9.66(7.20)$ & $6.90(5.87)$ & $4.11(4.61)$ & $5.60(5.46)$ \\
\hline
\end{tabular}




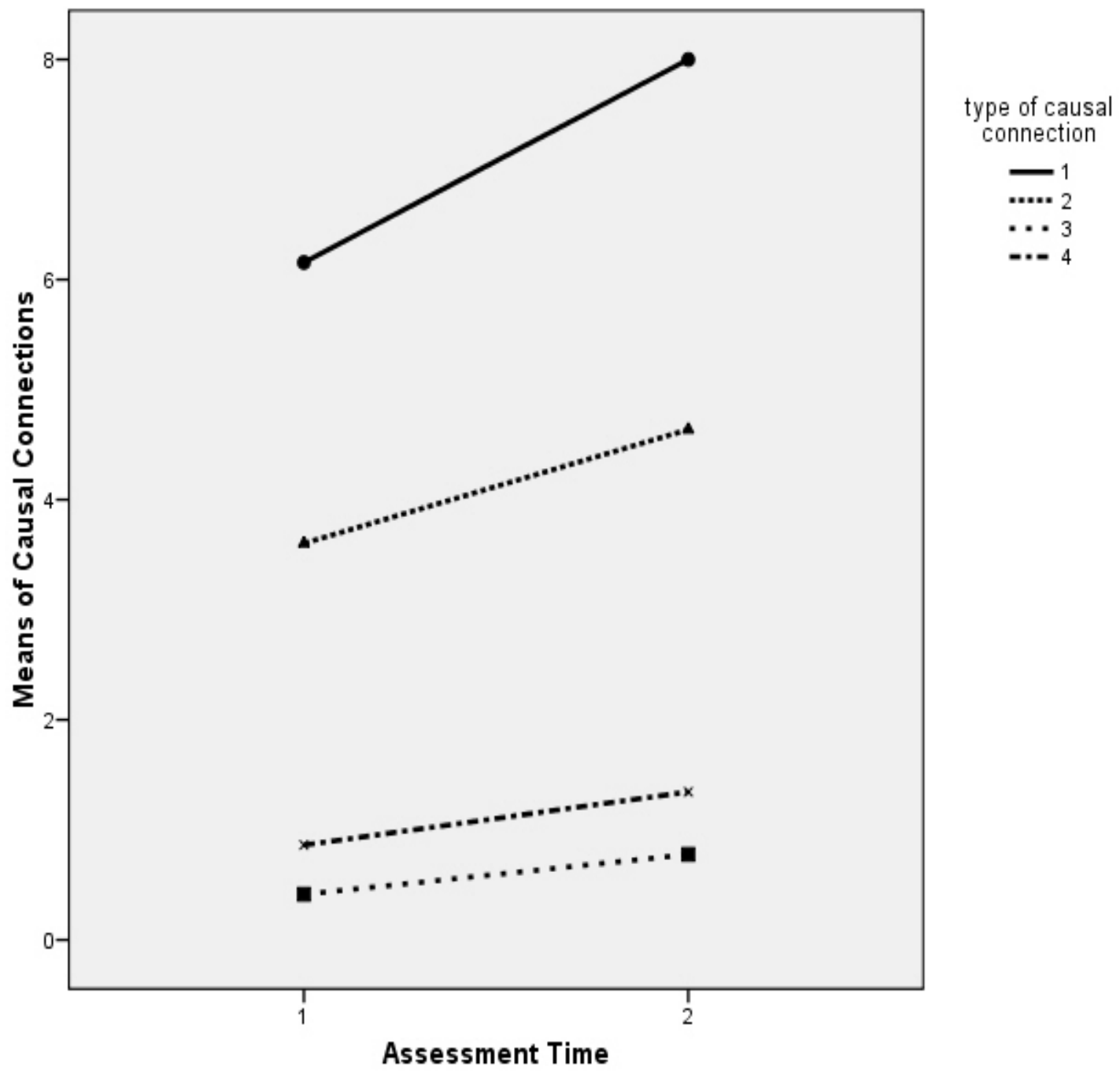

Figure 4. The production of the four types of causal connections across assessment time.

Type 1 is enabling connections, type 2 is physical connections, type 3 is motivational connections, and type 4 is psychological connections. 
Table 5

Correlations between Chronological Age and Storytelling Variables

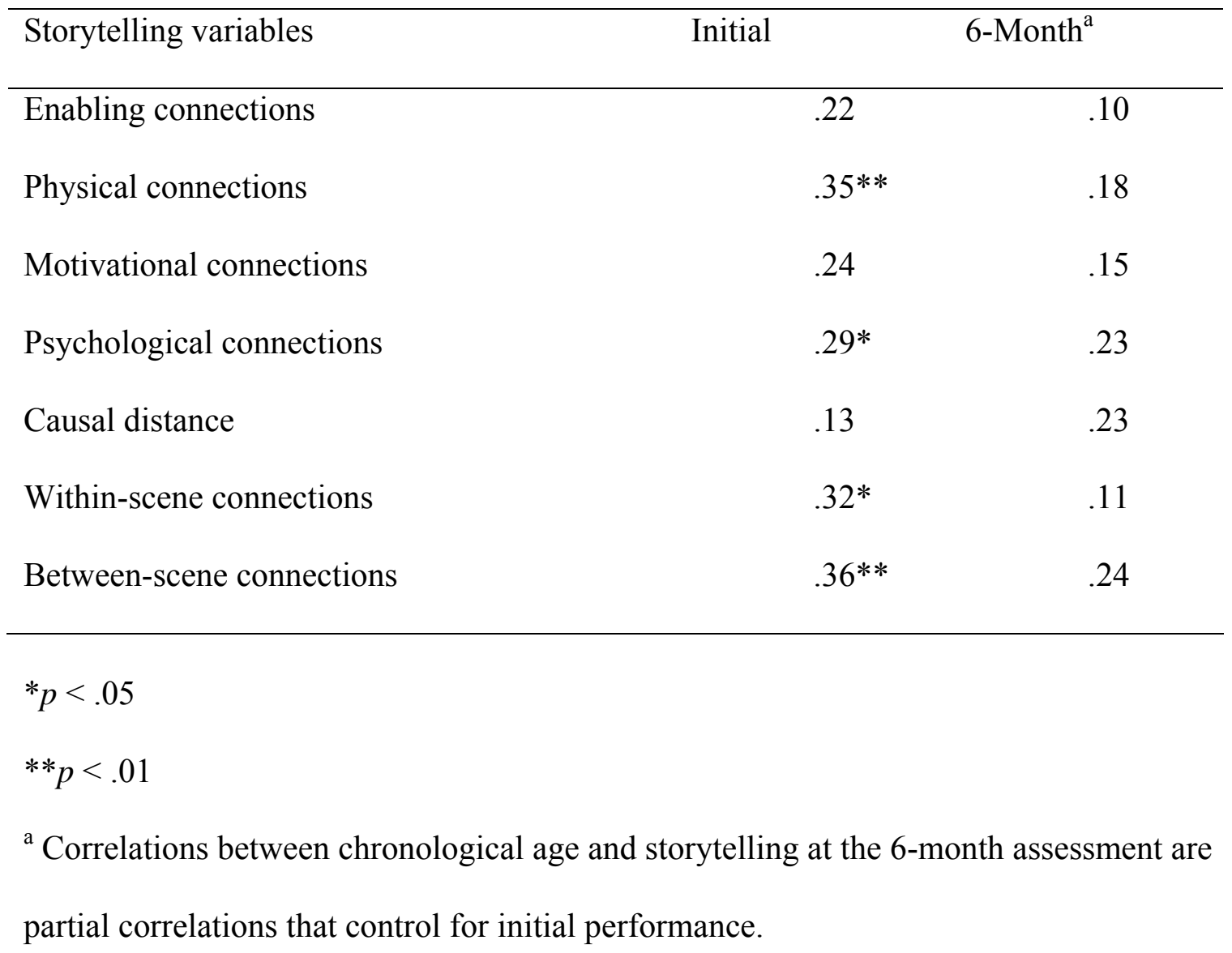


Table 6

Summary of Linear Regression Analysis for Variables Predicting Children's Use of Physical and Psychological Connections at the Initial Assessment

\begin{tabular}{|c|c|c|c|c|c|c|}
\hline \multirow[b]{2}{*}{ Variable } & \multicolumn{3}{|c|}{ Physical Connections } & \multicolumn{3}{|c|}{ Psychological Connections } \\
\hline & B & SE B & $\beta$ & B & SE B & $\beta$ \\
\hline \multicolumn{7}{|l|}{ Step 1} \\
\hline Chronological age & 0.16 & 0.06 & $.35 * *$ & 0.07 & 0.03 & $.29 *$ \\
\hline \multicolumn{7}{|l|}{ Step 2} \\
\hline Chronological age & 0.16 & 0.06 & $.34^{*}$ & 0.10 & 0.03 & $.40 * *$ \\
\hline PE vs. other goals & 0.44 & 1.13 & .06 & 1.88 & 0.57 & $.48 * *$ \\
\hline NI vs. other goals & 0.89 & 1.09 & .12 & 0.49 & 0.55 & .13 \\
\hline \multicolumn{7}{|l|}{ Step 3} \\
\hline Chronological age & -0.03 & 0.11 & -.06 & -0.004 & 0.06 & -.02 \\
\hline PE vs. other goals & 0.35 & 1.13 & .05 & 1.95 & 0.55 & $.49 * *$ \\
\hline NI vs. other goals & 0.52 & 1.10 & .07 & 0.37 & 0.54 & .10 \\
\hline Age X PE & 0.24 & 0.15 & .35 & 0.18 & 0.07 & $.48^{*}$ \\
\hline Age X NI & 0.25 & 0.15 & .31 & 0.08 & 0.08 & .18 \\
\hline
\end{tabular}

Note. For physical connections, $R^{2}=.12$ for Step $1(p=.008), \Delta R^{2}=.01(p>.05)$ for Step $2, \Delta R^{2}=.05(p>.05)$ for Step 3. For psychological connections, $R^{2}=.09$ for Step 1 $(p=.026), \Delta R^{2}=.17(p=.005)$ for Step $2, \Delta R^{2}=.09(p=.039)$ for Step 3 .

$* p<.05$

$* * p<.01$ 
Table 7

Summary of Linear Regression Analysis for Variables Predicting Children's Use of Within-Scene and Between-Scene Connections at the Initial Assessment

\begin{tabular}{|c|c|c|c|c|c|c|}
\hline \multirow[b]{2}{*}{ Variable } & \multicolumn{3}{|c|}{ Within-Scene Connections } & \multicolumn{3}{|c|}{ Between-Scene Connections } \\
\hline & B & SE B & B & B & SE B & $\beta$ \\
\hline \multicolumn{7}{|l|}{ Step 1} \\
\hline Chronological age & 0.22 & 0.09 & $.32 *$ & 0.15 & 0.05 & $.36 * *$ \\
\hline \multicolumn{7}{|l|}{ Step 2} \\
\hline Chronological age & 0.22 & 0.09 & $.31^{*}$ & 0.13 & 0.05 & $.30 *$ \\
\hline PE vs. other goals & 0.30 & 1.79 & .03 & -0.33 & 1.00 & -.05 \\
\hline NI vs. other goals & 1.01 & 1.73 & .09 & 1.95 & 0.97 & $.29 *$ \\
\hline \multicolumn{7}{|l|}{ Step 3} \\
\hline Chronological age & -0.04 & 0.18 & -.05 & -0.06 & 0.10 & -.14 \\
\hline PE vs. other goals & 0.05 & 1.79 & .01 & -0.51 & 0.98 & -.07 \\
\hline NI vs. other goals & 0.41 & 1.74 & .04 & 1.52 & 0.96 & .23 \\
\hline Age X PE & 0.30 & 0.23 & .28 & 0.22 & 0.13 & .34 \\
\hline Age X NI & 0.42 & 0.25 & .33 & 0.30 & 0.13 & $.39 *$ \\
\hline
\end{tabular}

Note. For within-scene connections, $R^{2}=.10$ for Step $1(p=.015), \Delta R^{2}=.01(p>.05)$ for Step $2, \Delta R^{2}=.05(p>.05)$ for Step 3. For between-scene connections, $R^{2}=.13$ for Step 1 $(p=.006), \Delta R^{2}=.10(p=.04)$ for Step $2, \Delta R^{2}=.07(p>.05)$ for Step 3 .

$* p<.05$

$* * p<.01$ 


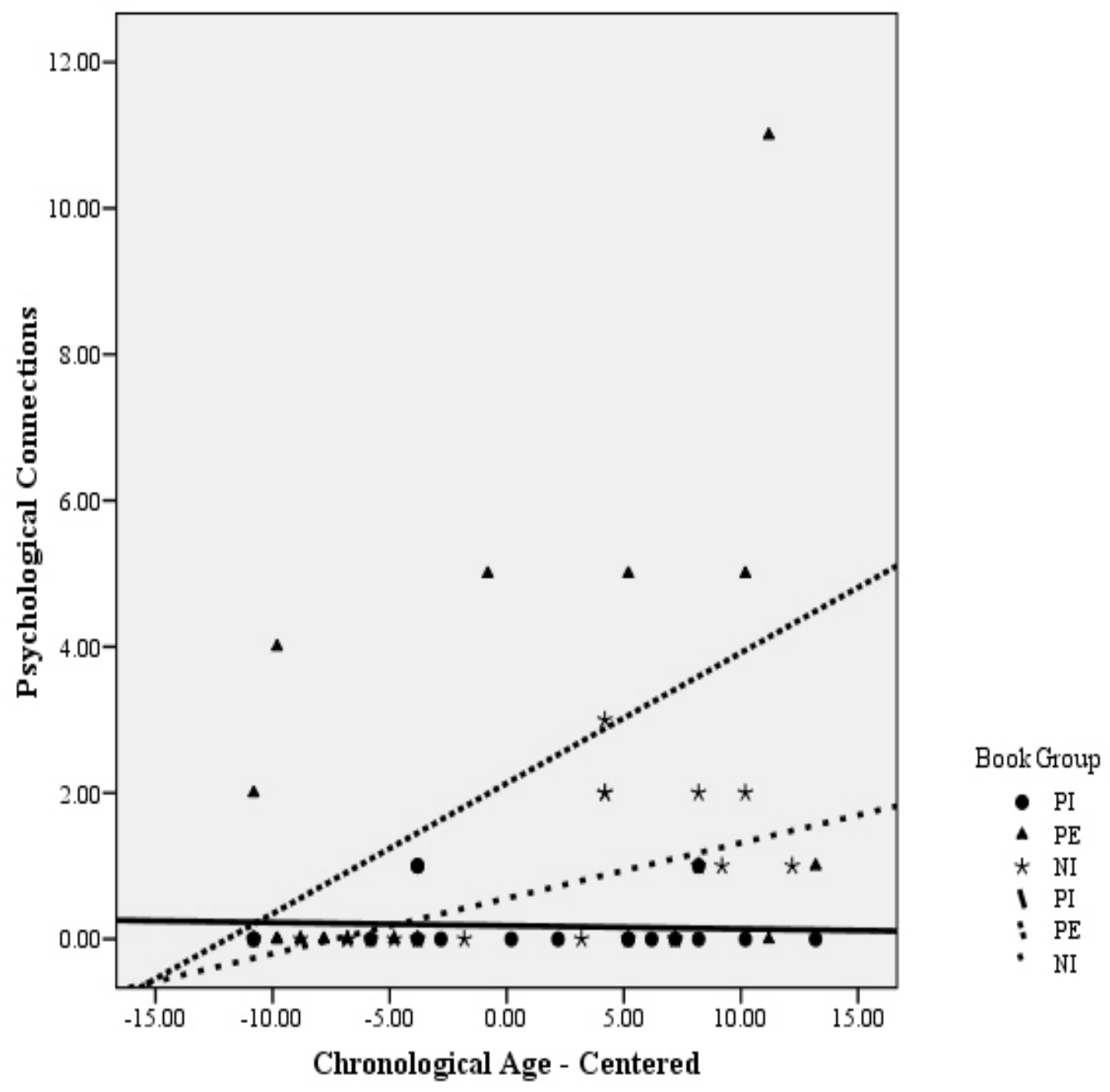

Figure 5. The production of psychological connections according to goal complexity at the initial assessment 
Table 8

Correlations between Goal Complexity and Storytelling Variables that Control for Chronological Age

\begin{tabular}{|c|c|c|c|c|c|c|}
\hline \multirow[b]{2}{*}{ Storytelling variables } & \multicolumn{3}{|l|}{ Initial } & \multicolumn{3}{|l|}{ 6-Month } \\
\hline & PE & NI & PI & $\mathrm{PE}$ & NI & PI \\
\hline Total connections & -.10 & .19 & -.10 & -.06 & .19 & -.13 \\
\hline Enabling connections & $-.31 *$ & .23 & .07 & -.22 & $.32 *$ & -.09 \\
\hline Physical connections & -.01 & .10 & -.10 & .24 & -.25 & .00 \\
\hline Motivational connections & $-.27 *$ & $.45^{* *}$ & -.20 & $-.38 * *$ & $.37 * *$ & .03 \\
\hline Psychological connections & $.41 * *$ & -.13 & $-.28 *$ & $.34^{*}$ & .02 & $-.37 * *$ \\
\hline Story nodes & .20 & -.06 & -.14 & .10 & .17 & $-.27 *$ \\
\hline Causal distance & -.16 & .21 & -.06 & .07 & -.09 & .01 \\
\hline Within-scene connections & -.02 & .08 & -.06 & -.01 & .17 & -.16 \\
\hline Between-scene connections & -.21 & $.33 *$ & -.13 & -.20 & .19 & .02 \\
\hline Overall goal & -.19 & .20 & -.03 & $-.65 * *$ & $.47 * *$ & .22 \\
\hline Outcome & .23 & -.06 & -.18 & -.04 & -.15 & .19 \\
\hline Overall coherence & -.14 & .07 & .07 & -.11 & .16 & -.05 \\
\hline Experimenter prompts & .02 & -.07 & .06 & .17 & -.14 & -.04 \\
\hline$* p<.05$ & & & & & & \\
\hline$* * p<.01$ & & & & & & \\
\hline
\end{tabular}


Table 9

Summary of Hierarchical Regression Analysis for Variables Predicting Children's Use of Motivational Connections at the Initial Assessment

\begin{tabular}{llll}
\hline Variable & B & SE B & B
\end{tabular}

Step 1

Chronological age

$0.03 \quad 0.02$

.24

Step 2

Chronological age

$0.02 \quad 0.02$

.17

PE vs. other goals

$-0.09$

0.29

$-.05$

NI vs. other goals

0.82

0.28

$.42^{* *}$

Step 3

Chronological age

$-0.01$

0.03

$-.09$

PE vs. other goals

$-0.19$

0.28

$-.10$

NI vs. other goals

0.70

0.27

$.36^{*}$

Age X PE

0.01

0.04

.06

Age X NI

0.09

0.04

$.38 *$

Note. $R^{2}=.06$ for Step $1(p>.05), \Delta R^{2}=.19(p=.002)$ for Step $2, \Delta R^{2}=.09(p=.045)$ for Step 3.

$$
\begin{aligned}
& * p<.05 \\
& * * p<.01
\end{aligned}
$$




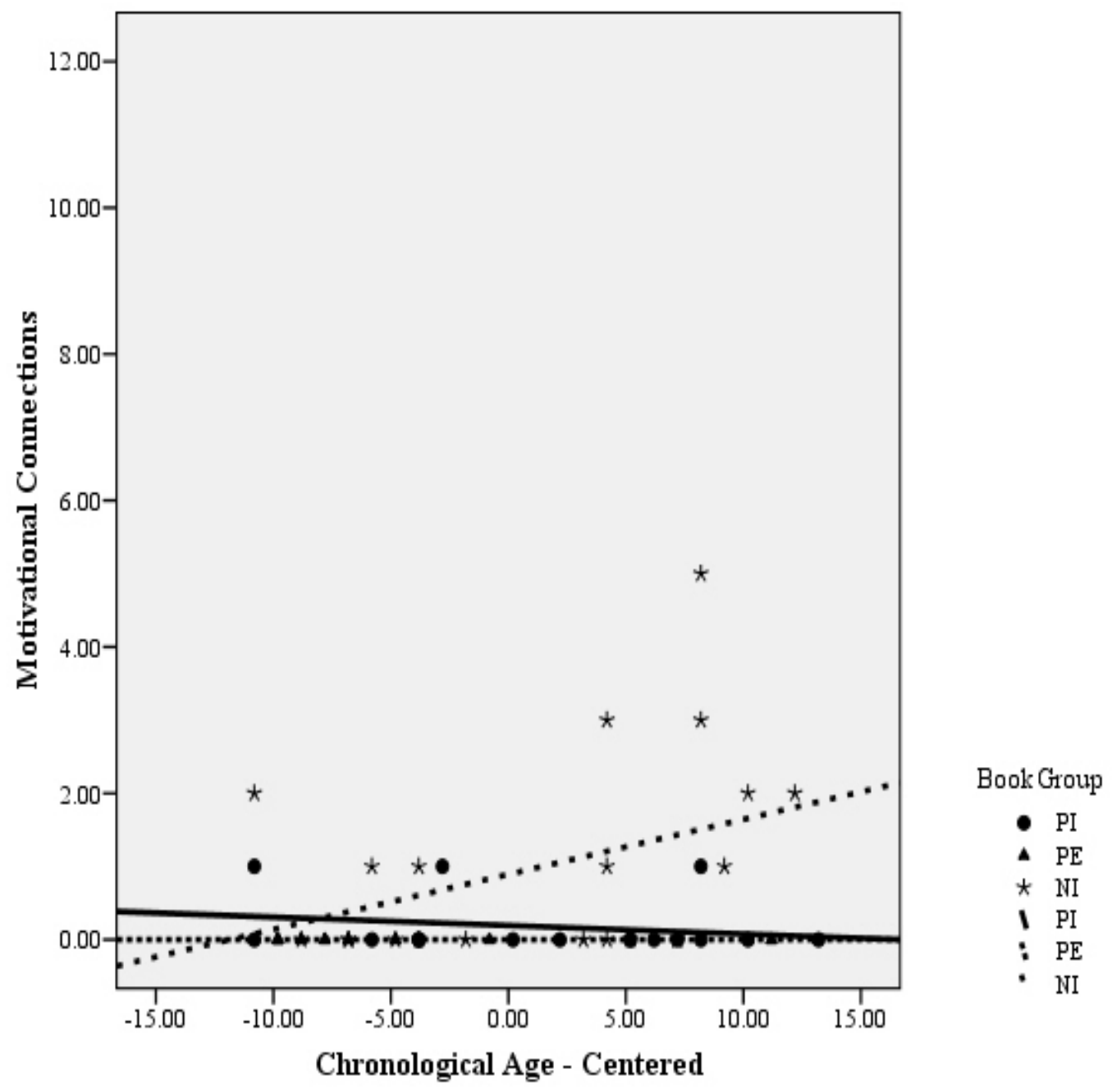

Figure 6. The production of motivational connections according to goal complexity at the initial assessment 
Table 10

Summary of Multiple Regression Analysis for Variables Predicting Children's Use of Psychological Connections at the 6-Month Assessment

\begin{tabular}{llll}
\hline Variable & B & SE B & B
\end{tabular}

Step 1

Chronological age

0.06

0.03

.24

Initial psychological connections

$-0.03$

0.14

$-.03$

Step 2

Chronological age

Initial psychological connections

PE vs. other goals

NI vs. other goals

Step 3

Chronological age

Initial psychological connections

PE vs. other goals

NI vs. other goals

Age X PE

Age X NI

0.03

0.04

1.87

1.06

0.60

0.03

.12

0.13

.04

$.49 * *$

.25

$\begin{array}{ll}0.58 & .49 \\ 0.60 & .25\end{array}$

2

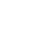


Table 11

Summary of Multiple Regression Analysis for Variables Predicting Children's

Production of an Overall Goal at the 6-Month Assessment

\begin{tabular}{llll}
\hline Variable & B & SE B & $\operatorname{Exp}(B)$
\end{tabular}

Step 1

Chronological age

0.02

0.04

1.02

Initial overall goal

$-0.28$

0.56

0.76

Step 2

$\begin{array}{lccc}\text { Chronological age } & 0.10 & 0.06 & 1.10 \\ \text { Initial overall goal } & -0.53 & 0.80 & 0.59 \\ \text { PE vs. other goals } & 3.13 & 0.99 & 22.93^{* *} \\ \text { NI vs. other goals } & -1.64 & 1.19 & 0.20\end{array}$

Step 3

$\begin{array}{lrrc}\text { Chronological age } & 0.19 & 0.13 & 1.21 \\ \text { Initial overall goal } & -0.61 & 0.83 & 0.55 \\ \text { PE vs. other goals } & 3.39 & 1.23 & 29.77^{* *} \\ \text { NI vs. other goals } & -143.80 & 14238.98 & 0 \\ \text { Age X PE } & -0.17 & 0.15 & 0.85 \\ \text { Age X NI } & 14.67 & 1451.48 & 2360269.00\end{array}$

Note. $R^{2}=.01$ for Step $1, R^{2}=.41$ for Step 2, $R^{2}=.46$ for Step 3 .

${ }^{*} p<.05$

${ }^{* *} p<.01$ 
Table 12

Descriptions of Attention Variables Measured During the Three Attention Games

Attention Variables Description

Alert median reaction time (A- Median of the reaction time for all alert task trials. MRT)

Beep alert MRT

No-beep alert MRT

200, 500, 1000, 2500 Alert MRT

Orienting MRT

Incompatible orienting MRT

Compatible orienting MRT

Spatial conflict MRT

Incompatible spatial conflict MRT

Compatible spatial conflict MRT
Median reaction time for alert trials that are preceded by an auditory stimulus.

Median reaction time for alert trials that are not preceded by an auditory stimulus.

Median reaction time for alert trials according to stimulus onset interval (i.e. 200, 500, 1000, 2500 $\mathrm{ms})$.

Median of the reaction time for all orienting task trials.

Median reaction time for incompatible orienting trials.

Median reaction time for compatible orienting trials.

Median of the reaction time for all spatial conflict task trials.

Median reaction time for incompatible spatial conflict trials.

Median reaction time for compatible spatial conflict trials. 
Table 13

Attention Game Means and Standard Deviations for the Entire Sample and According to Gender

\begin{tabular}{|c|c|c|c|}
\hline Attention game variables & $\begin{array}{l}\text { Boys } \\
(\mathrm{N}=27)\end{array}$ & $\begin{array}{l}\text { Girls } \\
(\mathrm{N}=31)\end{array}$ & Total sample \\
\hline Alerting accuracy & $0.97(0.03)$ & $0.98(0.03)$ & $0.98(0.03)$ \\
\hline Alerting beep MRT & $974.91(160.79)$ & $924.85(180.18)$ & $948.16(171.79)$ \\
\hline Alerting no-beep MRT & $1002.52(214.60)$ & $969.40(210.00)$ & $984.82(210.94)$ \\
\hline Orienting accuracy & $0.97(0.05)$ & $0.98(0.03)$ & $0.97(0.04)$ \\
\hline Orienting compatible MRT & $1222.28(265.90)$ & $1207.82(370.14)$ & $1214.55(323.12)$ \\
\hline $\begin{array}{l}\text { Orienting incompatible } \\
\text { MRT }\end{array}$ & $1297.06(391.23)$ & $1227.84(282.88)$ & $1260.06(336.37)$ \\
\hline Spatial conflict accuracy & $0.88(0.21)$ & $0.88(0.15)$ & $0.88(0.18)$ \\
\hline $\begin{array}{l}\text { Spatial conflict compatible } \\
\text { MRT }\end{array}$ & $1826.67(574.77)$ & $1920.94(580.57)$ & $1877.05(574.76)$ \\
\hline $\begin{array}{l}\text { Spatial conflict incompatible } \\
\text { MRT }\end{array}$ & 2002.63 (483.99) & $2068.32(497.58)$ & $2037.74(488.11)$ \\
\hline \multicolumn{4}{|l|}{$* p<.05$} \\
\hline$* * p<.01$ & & & \\
\hline
\end{tabular}


Table 14

Correlations among Chronological Age and Attention Game Variables

\begin{tabular}{|c|c|c|c|c|c|c|c|}
\hline & 1 & 2 & 3 & 4 & 5 & 6 & 7 \\
\hline 1. Chronological age & & & & & & & \\
\hline 2. Alerting beep MRT & $-.50 * *$ & & & & & & \\
\hline 3. Alerting no-beep MRT & $-.58 * *$ & $.83 * *$ & & & & & \\
\hline 4. Orienting compatible MRT & $-.35 * *$ & $.51 * *$ & $.62 * *$ & & & & \\
\hline 5. Orienting incompatible MRT & $-.27 * *$ & $.49 * *$ & $.54 * *$ & $.66^{* *}$ & & & \\
\hline 6. Spatial conflict compatible MRT & $-.53 * *$ & $.43 * *$ & $.48 * *$ & $.54 * *$ & $.30^{*}$ & & \\
\hline 7. Spatial conflict incompatible MRT & $-.63 * *$ & $.51 * *$ & $.57 * *$ & $.61 * *$ & $.35 * *$ & $.70 * *$ & \\
\hline
\end{tabular}

$* p<.05$

$* * p<.01$

Note. Negative correlations indicate that MRT increases for one task as MRT decreases for the other task; responses becoming slower for one task as responses become faster for the other task. 
Table 15

Correlations between Attention Game and Storytelling Variables at the Initial Assessment that Control for Chronological Age and Vocabulary

\begin{tabular}{|c|c|c|c|}
\hline Storytelling variables & Alert & Orienting & Spatial Conflict \\
\hline Total connections & .01 & $-.27 *$ & .12 \\
\hline Enabling connections & .06 & -.17 & .12 \\
\hline Physical connections & -.01 & $-.32 *$ & .06 \\
\hline Motivational connections & .04 & -.08 & .02 \\
\hline Psychological connections & -.13 & -.12 & .11 \\
\hline Story nodes & -.02 & .06 & .11 \\
\hline Causal distance & $-.49 * *$ & -.08 & .16 \\
\hline Within-scene connections & .13 & -.23 & .13 \\
\hline Between-scene connections & -.20 & $-.28 *$ & .07 \\
\hline Overall goal & .12 & $-.29 *$ & .01 \\
\hline Outcome & -.13 & -.08 & .04 \\
\hline Overall coherence & -.02 & -.18 & .11 \\
\hline Experimenter prompts & -.17 & -.07 & $.27 *$ \\
\hline \multicolumn{4}{|l|}{$* p<.05$} \\
\hline$* * p<.01$ & & & \\
\hline
\end{tabular}


Table 16

Summary of Linear Regression Analysis for Variables Predicting the Distance of Children's Causal Connections at the Initial Assessment

\begin{tabular}{lccc}
\hline Variable & B & SE B & B \\
\hline Step 1 & 0.03 & 0.02 & .22 \\
KBIT vocabulary & 0.00 & 0.15 & .00 \\
Chronological age & & & \\
Step 2 & 0.02 & 0.02 & .18 \\
KBIT vocabulary & 0.02 & 0.01 & .19 \\
Chronological age & -3.18 & 0.74 & $-.52 * *$ \\
Alert priming score & -0.69 & 0.45 & -.18 \\
Orienting interference score & 0.87 & 0.64 & .16 \\
Spatial conflict interference score & & & \\
\hline
\end{tabular}

Note. $R^{2}=.05$ for Step $1(p>.05), \Delta R^{2}=.28(p<.001)$ for Step 2 .

$$
\begin{aligned}
& * p<.05 \\
& * * p<.01
\end{aligned}
$$


Table 17

Correlations between Attention Game and Storytelling Variables at the 6-Month Assessment that Control for Chronological Age, Vocabulary, and Initial Performance

\begin{tabular}{lccc}
\hline Storytelling variables & Alert & Orienting & Spatial Conflict \\
\hline Total connections & .07 & -.07 & -.06 \\
Enabling connections & .14 & -.25 & .04 \\
Physical connections & -.09 & .22 & -.14 \\
Motivational connections & -.05 & -.22 & -.01 \\
Psychological connections & .08 & .13 & -.10 \\
Story nodes & .14 & .11 & -.13 \\
Causal distance & -.01 & -.06 & -.11 \\
Within-scene connections & -.00 & -.01 & -.08 \\
Between-scene connections & .22 & -.24 & -.00 \\
Overall goal & -.05 & -.13 & -.04 \\
Outcome & -.03 & .09 & -.06 \\
Overall coherence & .01 & -.19 & .04 \\
Experimenter prompts & & & \\
\hline * & & & \\
\hline
\end{tabular}




\author{
DANIELLE D. BROWN \\ Department of Psychological and Brain Sciences \\ 317 Life Sciences Building \\ University of Louisville \\ Louisville, KY 40292 \\ Office: (502) 852-3694 \\ Lab: (502) 852-2348 \\ Fax: (502) 852-8904 \\ E-mail: danielle.brown@louisville.edu
}

\title{
EDUCATION
}

2003-Present, Ph.D. (candidate), Experimental Psychology-Cognitive \& Developmental Sciences. University of Louisville, Louisville, KY

Mentor and Lab Director: Barbara Burns, Ph.D.

Early Intervention for Multi-Risk Families Lab

December 2005, M.A., Experimental Psychology-Cognitive \& Developmental Sciences.

University of Louisville, Louisville, KY

Mentor and Lab Director: Barbara Burns, Ph.D.

Early Intervention for Multi-Risk Families Lab

1999-2003, B.A., Elementary Education and Psychology. American University,

Washington, DC

Magna cum laude

PROFESSIONAL EXPERIENCE AND HONORS

2007-present, Instructor, Department of Psychological and Brain Sciences, University of Louisville

2003-2005, University Fellowship, University of Louisville

2003, University Honors in Psychology, American University

\section{PROFESSIONAL ORGANIZATIONS}

Kentucky Psychological Association Graduate Student Affiliate

Society of Research in Child Development Graduate Student Member

American Psychological Association Graduate Student Affiliate (2003 - 2006)

Association for Psychological Sciences Graduate Student Affiliate (2003 - 2006)

PROFESSIONAL DEVELOPMENT

April 2006, Conference Co-Chair. Conference on Human Development 2006. Louisville, $\mathrm{KY}$.

2005-2006, APAGS Campus Representative. American Psychological Association 
July 2004, John Merck Fund Summer Institute on the Biology of Developmental Disabilities

\section{TEACHING INTERESTS}

Multicultural Psychology

Multi-Risk Families and Child Development

Cognitive Psychology

Developmental Psychology

Research Methods

Statistics

\section{TEACHING EXPERIENCE}

Fall 2007, PSYC-322 - Cognitive Processes

Fall 2007, PSYC-401 - Research Psychology (1 Independent Study student)

2003-2007, Participation each semester in training and supervision of 2 to 4 undergraduate research assistants in the Early Intervention for Multi-Risk Families Lab in collaboration with Dr. Barbara Burns (Psyc 401, 402, 405, 406). Louisville, KY.

Spring 2007, Graduate Teaching Assistant, Experimental Psychology (PSYC 302).

Department of Psychological and Brain Sciences, University of Louisville. Louisville, KY.

Fall 2006, Graduate Teaching Assistant, Quantitative Methods in Psychology (PSYC

301). Department of Psychological and Brain Sciences, University of Louisville.

Louisville, KY.

Fall 2005 - Spring 2006, Graduate Teaching Assistant, Cognitive Processes (PSYC 322).

Department of Psychological and Brain Sciences, University of Louisville.

Louisville, KY.

Spring 2003, Student Teacher, Grade 4. Burning Tree Elementary School. Bethesda, MD.

Fall 2001-Spring 2003, Private Therapist. Bethesda, MD.

Fall 2002, Intern, Grades 1 and 2. John Eaton Elementary School. Washington, DC.

Summer 2002, Intern. Nassau-Suffolk Services-Autism: The Martin C. Barell School.

Levittown, NY.

\section{Guest Lectures}

April 2006, Cognitive Processes (PSYC 322). University of Louisville. Louisville, KY.

February 2006, Life Span and Development (PSYC 363). University of Louisville.

Louisville, KY.

January 2006, Diversity Issues in Psychology (PSYC 575). Western Illinois University. Macomb, IL.

\section{RESEARCH PROJECTS}

2006-Present, Understanding the Impact of Attention and Practice on Children's Storytelling. Mentor: Dr. Barbara M. Burns (University of Louisville) The development of causal reasoning is investigated in the light of the interaction between the family environment, individual differences in attention, and practice effects. It will be the first to investigate the ability to produce causal connections in children from 
low-income families. Causal connections are assessed during a storytelling task at four different times. The study also pilots assessments of the home environments for African American children living in poverty. The assessments are intended to examine the role of the family environment in the development of children's attention skills.

2004-2005, Understanding the Impact of Early Instruction in Latin on Early Literacy. Mentor: Dr. Barbara M. Burns (University of Louisville)

The project was a longitudinal study aimed at determining whether early instruction in Latin will accelerate literacy development in young children. The study compared literacy development of children in enrolled in a preschool's Latin program with a control group. Most of the assessments examined whether the role of attention and temperament also influenced early literacy. The results of the project have important implications for language and literacy development, interventions for early literacy, and early education.

2004-2005, Understanding the Impact of Early Childhood Education on Children's Math and Spatial Abilities. Mentor: Dr. Barbara M. Burns (University of Louisville) This project examined how piano training affects performance on measures of spatial abilities and mathematical skills. Spatial and math skills are assessed before piano training and at six months. The influence of individual differences in children's attentional skills, temperament, motivation, and home environment was also examined. The results of the project have important implications for cognitive, educational, and developmental research.

2003-2005, An Examination of Temperament and Attention in Children of Poverty. Mentor: Dr. Barbara M. Burns (University of Louisville)

This study investigated children's attentional skills and temperament. Attentional skills are assessed by children's performance on three computerized attention games and a naturalistic TV task. The children were also given a cognitive ability test, as well as school readiness measures of reading and mathematical ability. Parents completed a variety of questionnaires on the child's behavior and temperament, as well as questionnaires on self-behavior.

2003-2004, Temperament-Focused Parent Training. Mentor: Dr. Barbara M. Burns (University of Louisville)

The purpose of this study was to pilot an intervention for families who are at risk for unsuccessful development of attention/self-regulation, identify the utility of this intervention, and examine several factors that may moderate its effectiveness. The Temperament-focused Parent Training Program educates parents about their child's temperament and teaches individualized parenting skills. Parents attended the $1 \frac{1}{2}$ hour training sessions once a week for three weeks.

\section{GRANTS AND CONTRACTS}

Brown, D.D. (2007). Attention Regulation and Storytelling Ability in African American Children Attending Head Start Programs. NSF Postdoctoral Fellowship for Minorities (not funded, in preparation for resubmission)

Brown, D.D. (2007). Attention Regulation and Storytelling Ability in African American Children Attending Head Start Programs. NRSA Postdoctoral Fellowship (not funded, in preparation for resubmission)

Brown, D.D. (2007). Attention Regulation and Storytelling Ability in African American Children Attending Head Start Programs. Ford Foundation Diversity Fellowships (in preparation)

Postdoctoral Project (in preparation): Attention Regulation and Storytelling Ability in African American Children Attending Head Start Programs 
Mentors: Drs. Jean M. Ispa (U of Missouri-Columbia), Paul van den Broek (U of Minnesota), and Barbara M. Burns (U of Louisville)

The study will examine the influence of the home and family environments on school readiness in African American children living in poverty. Home environment will be assessed in the child's home using naturalistic observation and questionnaires. School readiness will be measures in terms of general self regulation skills and more specific story telling skills. Causal reasoning is assessed using a storytelling task. A parent-child storytelling task is used to assess the role of the parent in the development of attention and causal reasoning. The study is based on our previous research which relates individual differences in children's causal reasoning to children's attention and self regulation abilities. The study will also examine how racial socialization influences children's school readiness skills. This postdoctoral research will attempt to better characterize how parent-child interactions and cultural factors can support or limit school readiness in families of poverty and inform future intervention.

Brown, D. D. (Co-PI; 2004-2005) Understanding the Impact of Early Childhood Education on Children's Math and Spatial Abilities. Contract from Plainview Preschool, Inc. Louisville, KY.

\section{PUBLICATIONS}

Burns, B. M., Chang, F., Snyder, E., Robinson, J. B., Davis, D. W., Weatherholt, T., Strother, S., Harris, R. C., \& Brown, D. (2007; submitted). Specific attention skills and achievement in young children of poverty. Early Education \& Development.

Brown, D. D. (2007). Review of the book Keepin' On: The Everyday Struggles of Young Families in Poverty edited by Ispa, J. M., Thornburg, K. R., \& Fine, M. A. NHSA Dialog, 10(3-4), 1-2.

\section{RESEARCH PAPERS AND PRESENTATIONS}

Robinson, J. B., Brown, D. D. Chang, F., \& Burns, B. M. (in preparation). Attention regulation in children living in poverty: The impact of effortful control and home environment

Brown, D. D., Weatherholt, T. N., \& Burns, B. M. (in preparation). Do attentional skills relate to attention allocation to a televised story? A study of children from lowincome families. Developmental Psychology.

Brown, D. D., Harris, R. C., Burns, B. M. (in preparation). Motivation orientation and storytelling ability in young children.

Brown, D. D., Haynes, L. \& Burns, B. M. (in preparation). The relationship between parent-reported attention problems and attention skills in children from poverty.

Brown, D. D., Harris, R. C., Davis, D. W., Robinson, J. B., Snyder, E. H., Weatherholt, T. N., \& Burns, B. M. (March, 2007). Attention regulation in children from low SES families: The influence of child temperament and maternal sensitivity. Symposium paper presented at the Society for Research on Child Development's Biennial Conference. Boston, MA.

Harris, R. C., Brown, D. D., Davis, D. W., Robinson, J. B., Snyder, E. H., Weatherholt, T. N., \& Burns, B. M. (March, 2007). The relation of maternal hostility and children's negative affect to the development of motivation in children from 
poverty. Symposium paper presented at the Society for Research on Child Development's Biennial Conference. Boston, MA.

Burns, B. M., Brown, D. D., \& Harris, R. C. (March, 2007). Motivation orientation and storytelling ability in young children. Poster presentation at the Society for Research on Child Development's Biennial Conference. Boston, MA.

Harris, R. C., Brown, D. D., \& Burns, B. M. (March, 2007). The relation of spontaneous verbalizations to motivation orientation in young children. Poster presentation at the Society for Research on Child Development's Biennial Conference. Boston, MA.

Davis, D. W, Harris, R. C., Brown, D. D., Chang, F. C., Snyder, E. H., Robinson, J. B., Burns , B. M. (March, 2007). Attention Networks and Self-Regulated Attention in Preschool Children from Head Start. Poster presentation at the Society for Research on Child Development's Biennial Conference. Boston, MA.

*Lile, J., Brown, D., Richard, H., \& Burns, B. M. (February, 2007). The relationship between early language skills and the ability to make causal connections. Poster presentation at Posters at the Capitol. Frankfort, KY.

Brown, D. D. (November, 2006). The role of individual differences in attention in everyday skills. Research presentation to the Department of Psychological and Brain Sciences, University of Louisville. Louisville, KY.

Brown, D. D., Martin, M., Haynes, L. \& Burns, B. M. (April, 2006). A longitudinal study of narrative ability in young children. Poster presentation at the Conference on Human Development. Louisville, KY.

Brown, D. D., Martin, M., Squires, J., Haynes, L. \& Burns, B. M. (April, 2006). Characterizing storytelling in 3-and 4-year-old children. Poster presentation at the Conference on Human Development. Louisville, KY.

Brown, D. D., Weatherholt, T. N., Burns, B. M. (April, 2006). Do attentional skills relate to attention allocation to a televised story? A study of children from low-income families. Poster presentation at the Conference on Human Development. Louisville, KY.

*Martin, M., Brown, D., Haynes, L. \& Burns, B. (April, 2006). A longitudinal study of narrative ability in young children. Poster presentation at the University of Louisville Undergraduate Research Symposium. Louisville, KY.

Brown, D. (January, 2006). Attention and individual differences. Colloquium presentation to the Department of Psychology at Western Illinois University. Macomb, IL.

Harris, R. C., Brown, D. D., \& Burns, B. M. (July, 2005). Plainview Preschool Early Childhood Enrichment Programs Piano Math Keys@ \& Latin Locomotive $\subset$ [Technical Report]

*Becher, N., Harris, R. C., Brown, D. D., \& Burns, B. (April, 2005). Development of mastery motivation in young children. Poster presentation at the University of Louisville Undergraduate Research Symposium. Louisville, KY.

Davis, D. W., Snyder, E. H., \& Brown, D. D. (April, 2005). Attention-related behavior and child temperament in preschool children born with VLBW. Poster presentation at the Society for Research on Child Development's Biennial Conference. Atlanta, GA.

*Haynes, L., Weatherholt, T., Brown, D. D., \& Burns, B. (April, 2005). Attention skills and parent-reported attention problems in children from poverty. Poster 
presentation at the University of Louisville Undergraduate Research Symposium. Louisville, KY.

*Squires, J., Brown, D. D., Harris, R. C. \& Burns, B. (April, 2005). Characterizing storytelling in young children: Understanding causal reasoning. Poster presentation at the University of Louisville Undergraduate Research Symposium. Louisville, KY.

Burns, B., Chang, F., Snyder, E., Robinson, J. B., Davis, D. W., Weatherholt, T., Strother, S., Harris, R., \& Brown, D. (March, 2005). Research to practice for children of poverty. Poster presentation at the Third Annual Kentucky Innovation and Enterprise Conference. Kentucky.

Strother, S., Snyder, E., Harris, C., Brown, D., Robinson, J., \& Burns, B. (June, 2004). The development of attention networks and their relation to distraction. Paper presentation at the Hawaii International Conference on Social Sciences. Honolulu, HA.

Strother, S. A., Snyder E., Harris, C., Robinson, J., Lehman, E. B., Brown, D., \& Burns, B. M. (June, 2004). The effect of temperament and home environment on distractibility in Head Start children. Promoting Positive Development in Young Children: Strategies that Work, 734-735. Head Start's $7^{\text {th }}$ National Research Conference.

Weatherholt, T., Brown, D., Snyder, E., Wilcox, L., Cummins, R., Burns, B. M., Franco, S., Lorch, E., \& Milich, R. (June, 2004). The relationship between attention and comprehension of a televised story in children from low-income backgrounds. Promoting Positive Development in Young Children: Strategies that Work, 552553. Head Start's $7^{\text {th }}$ National Research Conference.

Weatherholt, Brown, D. D., T., Snyder, E., Nickels, A., Wilcox, L., Cummins, R., \& Burns, B. (April, 2004) An examination of the relationship between visual attention to a televised story and attentional abilities in children from poverty. Paper presentation at the Conference on Human Development. Washington, DC

*Haynes, L., Weatherholt, T., Brown, D. D., Cummins, R., Busse, C., \& Burns, B. (April, 2004). The relationship between parent reported attention difficulty and an assessment of attention skills in children from poverty. Poster presentation at the University of Louisville Undergraduate Research Symposium. Louisville, KY.

* undergraduate researcher

\section{PROFFESSIONAL SERVICE}

Mentor (February, 2005 - present). Big Brothers Big Sisters of Kentuckiana.

Judge (March, 2007). Louisville Science Fair. University of Louisville. Louisville, KY. Brown, D.D. \& Harris, R.C. (April, 2006). Rethinking school readiness. Mom's Club. Louisville, KY.

Brown, D. D. \& Harris, R. C. (March, 2005). Making connections early for later school success. Plainview School Parent Workshop. Louisville, KY.

Brown, D.D. \& Harris, R.C. (January, 2005). Rethinking school readiness. St. Francis Preschool Teacher Workshop. Louisville, KY.

Brown, D.D., Harris, R.C., Fentress, L., Becher, N., \& Squires, J. (November, 2004). The Power of Play. Friends School Parent Workshop. Louisville, KY. 
Brown, D.D. (October, 2005). Florida A\&M University Feeder Conference. Tallahassee, FL (University of Louisville's Graduate School and Psychological and Brain Sciences Department recruitment).

Brown, D.D. (March, 2004). Consultation with Peace Corps staff concerning early childhood education. Belmopan, Belize, CA.

Brown, D.D., Cadle, C.D., Farese, B.L., Harris, R.C., \& Molfese, D.L. (March, 2004). Consultation with Belize Ambassador to United Nations, Stuart Leslie, regarding planned Belize, CA workshops.

Molfese, D.L. \& Brown, D.D (March, 2004). Radio Interview. WAVE 105.9. Belize City, Belize, CA.

Panel Member (December, 2003). Society of Porter Scholars: Junior/Senior Seminar \#2 (Panel discussion concerning applying to graduate school). University of Louisville, Louisville, KY.

\section{Workshops for Teachers}

Brown, D.D., Harris, R.C., \& Weatherholt, T. (October, 2004). Rethinking school readiness. St. Francis Preschool. Louisville, KY.

Burns, B., Brown, D.D., Harris, R.C., Strother, S., Cummins, R., \& Weatherholt, T. (February, 2004). Parents, kids, and school success. Early Head Start. Louisville, KY.

\section{International Workshops for Teachers}

Brown, D.D., Harris, R.C., Cummins, R., \& Flores, P. (March, 2004). The TV guide: Families, television and choices. St. Martins Government Primary School. Salvapan, Belmopan, Belize, CA.

Brown, D.D., Harris, R.C., Flores, P. \& Molfese, V.J. (March, 2004). Getting kids ready for school. St. Martins Government Primary School. Salvapan, Belmopan, Belize, CA.

Cadle, C.D., Harris, R.C., Brown, D.D., \& Molfese, D.L. (March, 2004). Substance abuse: symptoms, statistics and treatment. St. Martins Government Primary School. Salvapan, Belmopan, Belize, CA.

Farese, B.L., Brown, D.D., Harris, R.C., \& Cadle, C.D., (March, 2004). HIV/AIDS: Education, prevention and intervention. St. Martins Government Primary School. Salvapan, Belmopan, Belize, CA.

Farese, B.L., Cadle, C.D., Brown, D.D., Harris, R.C., \& Molfese, D.L. (March, 2004). HIV/AIDS: Education, prevention and intervention. Ecumenical High School. Dangriga, Belize, CA.

Harris, R.C. \& Brown, D.D. \& Molfese, D.L. (March, 2004). Developmental disabilities. St. Martins Government Primary School. Salvapan, Belmopan, Belize, CA.

Harris, R.C. \& Brown, D.D. (March, 2004). Attention and school success. St. Martin's Government Primary School. Salvapan, Belmopan, Belize, CA.

Harris, R.C. \& Brown, D.D. (March, 2004). Ready to learn: Self-regulation and temperament. St. Martin's Government Primary School. Salvapan, Belmopan, Belize, CA. 


\section{International Workshops for Hospitals and Clinics}

Farese, B.L., Cadle, C.D., Brown, D.D., Harris, R.C., \& Molfese, D.L. (March, 2004). HIV/AIDS: Education, prevention and intervention. Southern Regional Hospital Medical Staff. Dangriga, Belize, CA.

Farese, B.L., Cadle, C.D., Brown, D.D., Harris, R.C., \& Molfese, D.L. (March, 2004). HIV/AIDS: Education, prevention and intervention. Western Regional Hospital Medical Staff. Belmopan, Belize, CA.

Harris, R.C. \& Brown, D.D. (March, 2004). Ready to learn: Self-regulation and temperament. Western Regional Hospital Medical Staff. Belmopan, Belize, CA.

\section{International Workshops for Students}

Farese, B.L., Cadle, C.D., Brown, D.D., Harris, R.C., \& Molfese, D.L. (March, 2004). HIV/AIDS and you. Ecumenical High School. Dangriga, Belize, CA (Workshop presented to 8 classes).

\section{COMPUTER SKILLS}

Statistical/Data Collection Packages - SPSS, The Observer (Noldus)

Word Processing - Microsoft Word

Other - Microsoft Power Point, Microsoft Excel, Microsoft Publisher, Quickbooks

\section{COURSE CURRICULUM RELATED TO PSYCHOLOGY}

Assessment

PSYC 622 Developmental Assessment

\section{Cognitive and Developmental Sciences}

PSYC 571 Cognitive Neuroscience

PSYC 603 Master's Research

PSYC 604 Attention Networks and Gazes

PSYC 604 Causal Relations and Attention

PSYC 604 Development of Narrative Ability

PSYC 604 Longitudinal of Achievement in Preschool Children

PSYC 604 Parent Reports of Attention

PSYC 604 Service Learning in Psychology

PSYC 604 Assessment of Attention in a Naturalistic Setting

PSYC 605 African American Family Environment

PSYC 605 Attention Networks and Gazes

PSYC 605 Attention to Television

PSYC 605 Children's Attention

PSYC 605 Cognitive Development

PSYC 605 Enrichment and Achievement

PSYC 605 Literacy and Story Production

PSYC 605 Parenting and Achievement

PSYC 605 Parent Reports of Attention

PSYC 605 Relations in Narrative

PSYC 605 Research on the Development of Attention

PSYC 605 Storytelling in Head Start Children

PSYC 605 Temperament and Cognitive Development 
PSYC 609 Developmental Psycholinguistics

PSYC 621 Cognitive Processes

PSYC 622 Analogy and Metaphor

PSYC 622 Cognitive Development

PSYC 622 Cognitive Aspects of Developmental Disabilities

PSYC 622 Social Cognition

PSYC 597 Forensic Psychology

PSYC 642 Behavioral Neuroscience

PSYC 638 Decision Making

PSYC 701 Dissertation Hours

Statistics

ECPY 694 Structural Equation Modeling

PSYC 514 Advanced Statistics I

PSYC 611 Advanced Statistics II

PSYC 612 Advanced Statistics III

\section{Teaching and Instruction}

PSYC 604 Teaching Writing to Undergraduates in Psychology 